Estudios Constitucionales, Año 10, No 2, 2012, pp. 281 - 322.

ISSN 0718-0195

Centro de Estudios Constitucionales de Chile Universidad de Talca

"Aplicabilidad en el ámbito interno y en tiempos de paz de las normas de ius cogens del Derecho Internacional Humanitario"

Regina Ingrid Díaz Tolosa

\title{
APLICABILIDAD EN EL ÁMBITO INTERNO Y EN TIEMPOS DE PAZ DE LAS NORMAS DE IUS COGENS DEL DERECHO INTERNACIONAL HUMANITARIO
}

\author{
PEREMPTORY InTERNATIONAL NORMS (IUS COGENS) IN \\ HUMANITARIAN INTERNATIONAL LAW, ITS APPLICABILITY IN TIMES \\ OF PEACE IN DOMESTIC COURTS
}

\author{
Regina Ingrid Díaz Tolosa* \\ Universidad Bernardo O’Higgins \\ ridiaz@uc.cl
}

RESUMEN: El Derecho Internacional Humanitario contiene normas perentorias de derecho internacional general (ius cogens) cuyo núcleo fundamental, la protección de la dignidad humana, coincide con el del Derecho Internacional de los Derechos Humanos. En opinión de la autora, esta convergencia permite utilizar ciertas normas del Derecho Internacional Humanitario, en el foro doméstico, fuera del ámbito de los conflictos armados, en los casos de violaciones de derechos fundamentales en tiempo de paz, al menos como un elemento de interpretación que coadyuve a determinar el sentido y alcance de las normas que protegen los derechos fundamentales.

ABSTRACT: The International Humanitarian Law contains peremptory norms of general international law (ius cogens). Their fundamental core, the human dignity protection, coincides with International Human Rights Law. In authoress opinion, this convergence allows to use International Humanitarian Law norms, in the internal forum, out of the area of the armed conflicts, in the cases of violations of fundamental rights in time of peace, at least as an element of interpretation that it contributes to determining the sense and scope of the norms that protect the fundamental rights.

PaLABRAS CLAVE: Derecho Internacional Humanitario. Ius cogens. Derecho Internacional de los Derechos Humanos. Ámbitos de aplicación de las normas internacionales.

KEY WORDS: International Humanitarian Law. Ius cogens. International Human Rights Law. International Law application areas.

\section{INTRODUCCIÓN}

El Derecho Internacional Humanitario (DIH) es un conjunto de normas internacionales que protegen los derechos fundamentales de las personas en caso

* Abogado, Magíster en Ciencia Jurídica y Candidata a Doctor, Pontificia Universidad Católica de Chile. Investigadora de la Dirección de Investigación y Relaciones Internacionales, Universidad Bernardo O’Higgins. Artículo recibido el 30 de noviembre de 2011 y aprobado para publicación el 18 de junio de 2012 . 
de conflicto armado. ${ }^{1}$ Sin embargo, ciertas normas del DIH, por ser normas de derecho consuetudinario y de derecho internacional general con la categoría de ius cogens internacional, cuyos principios fundantes son de aplicación imperativa, general y universal, debieran aplicarse en el foro interno de los Estados no sólo en tiempos de belicosidad, sino también en tiempos de paz, en caso de violación de derechos fundamentales, por lo menos como un mecanismo coadyuvante para la interpretación de la normativa aplicable en protección de la persona humana. ${ }^{2}$

Al considerar las fundamentales aspiraciones de la comunidad internacional en su conjunto, tales como la promoción de la paz y seguridad internacionales, por un aparte, y la promoción y protección de los derechos esenciales que emanan de la naturaleza humana, por otra, nadie podría afirmar que ciertos principios del DIH, v.g. el de humanidad, tendrían aplicación sólo en caso de conflictos bélicos. En efecto, la Corte Internacional de Justicia (CIJ), ya sostenía hacia 1949, que las consideraciones elementales de humanidad son principios generales y bien reconocidos que tienen aplicación tanto en tiempos de paz como en tiempos de guerra. ${ }^{3}$

Este estudio tiene por objeto indagar acerca de la posibilidad de aplicar parte del cuerpo normativo del DIH -propio de los conflictos armados-, en el ámbito interno, a vulneraciones de derechos fundamentales acaecidos en tiempos de paz, y la utilidad práctica de ello para el juez nacional.

En el desarrollo de la investigación se sugiere la posibilidad de aplicar normas del DIH, fuera del ámbito que le es propio -tiempos de guerra-, en los foros domésticos. En especial de aquellas normas del DIH de reconocido carácter de ius cogens, en caso de vulneraciones de derechos fundamentales en tiempos de paz. Ello sería posible debido a los puntos de coincidencia, convergencia o complementariedad, que permiten la aplicación simultánea, y no exclusiva ni excluyente, de las normas del Derecho Internacional de los Derechos Humanos (DIDH) y el DIH.

\footnotetext{
${ }^{1}$ Cfr. Comité Internacional de la Cruz Roja (2007), pp. 25 y 38; Ferraro (2007), p. 181; Santalla (2007), p. 57; Wilson (2007), pp. 67 y 68; Caldeira y Campos de Oliveira (2009), p. 609.

2 Cfr. Salmón (2004), p. 70; Comité Internacional de la Cruz Roja (2007), pp. 52-54.

${ }^{3}$ Corte Internacional de Justicia, The Corfu Channel Case, 9 de abril de 1949, p. 22. Criterio reafirmado en Corte Internacional de Justicia, Case concerning Military and Paramilitary Activities in and against Nicaragua (Nicaragua v. United States of America), 26 de junio de 1986, pár. 215. Cfr. GonZÁlez (2007), pp. 103 y 104.
} 
Quienes no estén de acuerdo con este planteamiento podrían esgrimir que las normas del DIH tienen una aplicación específica en tiempos de guerra, que el requisito esencial para aplicar estas normas es la existencia de un conflicto bélico internacional o interno efectivos; que no existen normas del DIH que gocen del carácter de ius cogens y, por último, que no tiene utilidad práctica el aplicar normas del DIH a las violaciones de los derechos fundamentales en tiempos de paz, pues son suficiente los mecanismos de garantía contemplados en el DIDH.

Pero, tratándose de los derechos más elementales del individuo, por qué hacer un distingo entre tiempos de guerra y tiempos de paz. La dignidad del hombre siempre ha de ser protegida, por supuesto que en tiempos de guerra su grado de vulnerabilidad es mayor, pero las razones de por qué resguardar los derechos del hombre en tiempos de guerra no divergen de las existentes para salvaguardarlos en tiempos de paz, todo lo contrario, si aún en el caso extremo de guerra, los derechos fundamentales de la persona han de ser preservados, con mayor razón tienen que ser amparados en caso de transgresión en tiempos de paz. ${ }^{4}$

Los derechos fundamentales en tiempos de guerra son protegidos por el DIH, y en tiempos de paz, son protegidos por el DIDH. Sin embargo, la convergencia de las normativas, debiese ser utilizada para complementarlas en aras de potenciar y mejorar la protección de la persona. Posiblemente no se pueda aplicar en forma directa cada una de las disposiciones de los Convenios de Ginebra (CG) a vulneraciones de derechos fundamentales acaecidas en tiempos de paz, pero sí darle aplicación indirecta a través de sus normas consuetudinarias y principios generales de carácter de ius cogens, reconociéndolos como un elemento que coadyuve a la interpretación de las normas que protegen los derechos fundamentales en tiempo de paz en beneficio de la persona humana. ${ }^{5}$ No se ha de olvidar que uno de los principios rectores del DIP moderno -posguerras mundiales- es el pro homine, es decir, aquel que aplica la normativa que permite dar a los derechos fundamentales una máxima protección. ${ }^{6}$

\footnotetext{
${ }^{4}$ Cfr. Díaz (2006), pp. 321-323; Schmahl (2006), p. 55; Iguyovwe (2008), p. 749; Caldeira y Campos de Oliveira (2009), p. 610.

5 Cfr. Salmón (2004), p. 73; Droege (2007), p. 3; Santalla (2007), pp. 58 y 66; Iguyovwe (2008), pp. 787-789; Caldeira y Campos de Oliveira (2009), pp. 613, 615, 618, 619.

${ }^{6}$ Cfr. Henderson (2004), pp. 87 y 91, Manili (2003), p. 223.
} 
En esta investigación se da cuenta de la evolución que ha tenido la institución del ius cogens internacional, abarcando actualmente no sólo el ámbito del Derecho de los Tratados, sino otros ámbitos del Derecho Internacional Público (DIP), y en especial el campo del DIH (apartados 1 y 2). Luego se desarrolla el argumento de la convergencia entre el DIH y el DIDH tratándose de normas de ius cogens con la finalidad de enfatizar el aporte complementario que hacen a la protección de los derechos fundamentales las normas de ius cogens del DIH (apartado 3). Finalmente, para ilustrar la utilidad de la aplicación en el foro interno de los Estados, de las normas de ius cogens del DIH -en el plano del DIDH-, se muestra cómo en Chile se han implementado las normas de ius cogens, cómo los tribunales chilenos han hecho esta aplicación, previa referencia del mecanismo de incorporación de las normas de ius cogens en el sistema jurídico chileno.

\section{EL IUS COGENS INTERNACIONAL}

Los primeros antecedentes del uso de esta institución en el Derecho Internacional datan de la primera mitad del s. XX. En doctrina, Verdross, en su artículo de 1937, acerca de los tratados prohibidos en el Derecho Internacional, explica el ius cogens dentro del ámbito del Derecho de los Tratados como normas imperativas de derecho internacional general que consisten en el principio general, universal y fundamental de prohibición de concluir tratados contra bonos mores. Dentro de éstos, aquellos que ponen en peligro los derechos fundamentales e impiden las tareas de las naciones civilizadas reconocidas universalmente tales como el mantenimiento del orden público, la defensa de los Estados contra ataques externos, el bienestar físico y psíquico de sus ciudadanos, y la protección de los nacionales fuera del Estado. ${ }^{7}$ Mientras que, a nivel jurisprudencial, el concepto es utilizado en el ámbito del DIP, por primera vez en 1934. El juez alemán SCHÜCKING de la Corte Permanente de Justicia Internacional, en su voto disidente en el Caso Oscar Chinn, incorpora la expresión ius cogens y aunque no la define ni indica su naturaleza, sostiene que acarrea como consecuencia la nulidad de todo acto contrario a estas normas. ${ }^{8}$

\footnotetext{
7 Verdross (1937), pp. 572 y 577.

${ }^{8}$ Corte Permanente de Justicia Internacional, Case Oscar Chinn (Britain vs. Belgium), 12 de diciembre de 1934, Series A/B No 63, voto del juez SCHÜCKING, p. 149.
} 
Luego de las atrocidades sufridas en las guerras mundiales, se intensifica la idea de existir bases fundamentales comunes a los Estados civilizados, y en especial que el derecho no puede consistir en un ordenamiento estructurado formalmente sin considerar el contenido de sus normas, por tanto la presencia de normas de ius cogens ${ }^{9}$ en el Derecho Internacionales reafirmado y reconocido a nivel positivo en la Convención de Viena sobre el Derecho de los Tratados (CVDT), pero circunscrito a este ámbito del Derecho de los Tratados, como una causal de nulidad de los tratados: Los Estados no son libres para concluir tratados sobre cualquier materia, ellos deben respetar las normas de ius cogens y en ese sentido no pueden pactar algo contrario a ellas, pues si no el tratado carecería de valor. ${ }^{10}$

En la actualidad, el ius cogens internacional trasciende el ámbito del Derecho de los Tratados. A modo de ejemplo, dentro del sistema regional americano de protección de los derechos de las personas, se puede destacar que la Corte Interamericana de Derechos Humanos (CtIDH) reconoce expresamente que el ius cogens ha alcanzado el derecho internacional general y los propios fundamentos del orden jurídico internacional. Lo cual revela una gradual emergencia de un derecho internacional universal que asegure los intereses y valores más fundamentales de la comunidad internacional como un todo. ${ }^{11}$ Además, se han de considerar las recomendaciones o informes de la Comisión Interamericana de Derechos Humanos, pues si bien no es un tribunal internacional cuyas decisiones sean vinculantes, es un cuerpo de expertos independientes que interpreta de forma autorizada el Derecho internacional. ${ }^{12}$ Este órgano, en 1987, a propósito del caso de Estados Unidos acerca de la aplicación de la pena de muerte a dos menores de 18 años $^{13}$, afirma que el concepto de ius cogens se deriva de una orden superior de normas legales establecidas en tiempos antiguos y que no

\footnotetext{
${ }^{9}$ Cfr. Scheuner (1967), p. 521; Troncoso (1988), p. 73; Weisburd (1995), p. 12.

${ }^{10}$ Vid. Art. 53 de la Convención de Viena sobre el Derecho de los Tratados de 1969.

${ }^{11}$ Corte Interamericana de Derechos Humanos, Opinión Consultiva sobre la Condición Jurídica y Derechos de los Migrantes Indocumentados, 17 de septiembre de 2003, Serie A No 18, párs. 4, 99-101 y 110.

${ }^{12}$ Cfr. Fox (1988), pp. 602 y 603.

${ }^{13}$ Cabe recordar que si bien Estados Unidos no ha ratificado la Convención Americana de Derechos Humanos, siendo un Estado miembro de la OEA, le es aplicable la normativa referente a los Estados que no son parte de la Convención (arts. 48 a 50 del Reglamento de la Comisión Interamericana de Derechos Humanos, y arts. 18 y 20 de su Estatuto), en virtud de la cual, la Comisión es competente para "examinar las comunicaciones que le sean dirigidas y cualquier información disponible; dirigirse al gobierno de cualquiera de los Estados miembros no partes en la Convención con el fin de obtener las infor-
} 
pueden ser contravenidos por las leyes del hombre o de las naciones. Agrega que los publicistas las han descrito como aquellas normas que abarcan el orden público internacional, es decir, reglas que han sido aceptadas, explícitamente en un tratado o tácitamente por costumbre, como necesarias para proteger el interés público de la sociedad de naciones o para mantener los niveles de moralidad pública reconocidos por ellos. ${ }^{14}$

\section{RECONOCIMIENTO DOCTRINARIO Y JURISPRUDENCIAL DEL CARÁCTER DE IUS COGENS DE LAS NORMAS DEL DIH}

\section{Normas del DIH con carácter de ius cogens de acuerdo a la doctrina}

La Comisión de Derecho Internacional que preparó el texto que luego sería la CVDT no quiso, en definitiva, incluir un listado de normas de ius cogens en el artículo 53 de la Convención por considerarlo no sólo de difícil realización, sino también innecesario. ${ }^{15}$ Sin embargo, en sus actas es posible encontrar los ejemplos que los comisionados consideraron al momento de discutir la inclusión del ius cogens en la Convención. Entre ellos podemos mencionar los crimenes de lesa humanidad ${ }^{16}$ y las normas consuetudinarias y de los principios fundamentales del DIH, en especial del artículo $3^{\circ}$ común a los cuatro CG. ${ }^{17}$

En materia de crímenes de lesa humanidad, puede constatarse que la prohibición de la tortura, norma reconocida en doctrina ${ }^{18}$ como norma de ius cogens, no está permitida bajo ninguna circunstancia por diversos instrumentos

\footnotetext{
maciones que considere pertinentes y formularles recomendaciones, cuando lo considere apropiado, para hacer más efectiva la observancia de los derechos humanos fundamentales" (art. 20 b) Estatuto).

${ }^{14}$ Comisión Interamericana de Derechos Humanos, Informe No 3/87, Caso 9647, Estados Unidos, 1987, párs. 54 y 55 .

15 Cfr. Sinclair (1973), p. 21.

${ }^{16}$ Cfr. Tunkin (1974), p. 93; Whiteman (1977), p. 626; Weisburd (1995), p. 23; Bustos (2000), p. 161; Nogueira (2000), p. 224; Drnas (2002), p. 15; Paulus (2005), p. 306; Brownlie (2008), p. 511.

17 Cfr. Sinclair (1973), pp. 123 y 124; Meron (1987), pp. 350, 355; Gowlland(1994), p. 93; Mangas (1999), p. 150; Crawford (2004), p. 294; Paulus (2005), p. 306; Shelton (2006), p. 303.

18 Cfr. Whiteman (1977), p. 626; Lippman (1979), p. 27; Belsky et al. (1989), p. 389; Orentlicher (1991), p. 2582; Bassiouni (1996), p. 68; Nogueira (2000), p. 224; Bou (2002), pp. 280 y ss.; CraWford (2004), pp. 232 y 294; De Wet (2004), p. 99; Orakhelashvili (2006), p. 43; Cohen (2007), p. 111; Kutz (2007), p. 258 n. 85; Mc Gregor (2007), p. 71, Criddle y Fox Decent (2009), p. 331.
} 
generales y universales sobre derechos humanos ${ }^{19}$. En el campo del DIH, está expresamente prohibida en los cuatro CG de 1949 (artículo 3º común; artículo 17 del III Convenio relativo al trato debido a los prisioneros de guerra; artículos 31, 32, 100, 146 y 147 del IV Convenio relativo a la protección debida a las personas civiles en tiempo de guerra) y sus dos Protocolos Adicionales de 1977 (artículo 75 del I Protocolo relativo a la protección de las víctimas de los conflictos armados internacionales, artículo 4 del II Protocolo relativo a la protección de las víctimas de los conflictos armados sin carácter internacional (I y II PCG, respectivamente).

En relación a la prohibición del genocidio ${ }^{20}$, la Convención para la Prevención y la Sanción del Delito de Genocidio de 1948 (CPSDG), confirma que el genocidio, ya sea cometido en tiempos de paz o en tiempos de guerra, es un delito de derecho internacional que los Estados Partes se comprometen a prevenir y a sancionar. ${ }^{21}$

19 Vid. la Declaración Universal de los Derechos Humanos (DUDH) (art. 5), el Pacto Internacional de Derechos Civiles y Políticos (PIDCP) (art. 7); los siguientes instrumentos regionales sobre derechos humanos: la Declaración Americana de Derechos y Deberes del Hombre (DADH) (art. 26), la Convención Americana sobre Derechos Humanos (CADH) (art. 5.2), el Convenio Europeo de Derechos Humanos (ConEDH) (art. 3), Carta de Derechos Fundamentales de la Unión Europea (CDFUE) (art. 4o), la Carta Africana de Derechos Humanos y de los Pueblos (CAfDHP) (art. 5), la Declaración de El Cairo sobre Derechos Humanos en el Islam (DCDHI) (art. 20), y la Carta Árabe de Derechos Humanos ( $\mathrm{CArDH})\left(\right.$ art. $\left.8^{\circ}\right)$; y los instrumentos especializados sobre prohibición y prevención de la tortura: la Convención de la Organización de las Naciones Unidas (ONU) contra la tortura y otros tratos o penas crueles, inhumanos o degradantes; la Declaración de la ONU sobre la protección de todas las personas contra la tortura y otros tratos o penas crueles, inhumanos o degradantes; la Convención interamericana para prevenir y sancionar la tortura; y el Convenio Europeo para la prevención de la tortura y otros tratos inhumanos o degradantes. También es posible encontrar su prohibición y castigo en el ámbito del Derecho Penal Internacional, específicamente en los estatutos de Tribunales internacionales: Estatuto del Tribunal Militar Internacional de Nüremberg (ETMN) (art. 6 c)), Estatuto del Tribunal Penal Internacional para la ex Yugoslavia (ETPIY) (art. 2 b) y 5 f)), Estatuto del Tribunal Penal Internacional para Ruanda (ETPIR) (arts. 3 f), 4 a)), Estatuto del Tribunal Penal Internacional (ETPI) (arts. $7^{\circ}, 8^{\circ}$ y 55$)$.

${ }^{20}$ Cfr. Scheuner (1967), p. 526; Barberis (1970), p. 35; Paul (1971), p. 38; Puceiro (1974), p. 70; Whiteman (1977), p. 625; BelsKy et al. (1989), p. 389; Ford (1994), p. 147; WeISBURD (1995), p. 22; Bassiouni (1996), p. 68; Benadava (1997), p. 54; Nogueira (2000), p. 224; Roberts (2001), p. 783; Drnas (2002), p. 15; Crawford (2004), pp. 232 y 293, Paulus (2005), p. 306, Milanovic (2006), p. 557; Cohen (2007), p. 71; Brownlie (2008), p. 511; Criddle y Fox-DeCent (2009), p. 331; Lepard (2010), p. 249.

${ }^{21}$ También es posible encontrar su prohibición y castigo en el ámbito del Derecho Penal Internacional, específicamente en los estatutos de Tribunales internacionales: ETMN (art. 6 c)), ETPIY (art. 4o), 
También la doctrina reconoce el carácter de ius cogens de la prohibición del crimen del apartheid ${ }^{2}$, la cual se encuentra recogida en instrumentos generales y universales de derechos humanos, como prohibición de discriminación racial $^{23}$; en tratados regionales sobre derechos humanos ${ }^{24}$; en instrumentos especializados sobre prohibición del apartheid ${ }^{25}$; en estatutos de tribunales internacionales ${ }^{26}$; y ciertamente, en instrumentos pertenecientes al DIH: CG (artículo $3^{\circ}$ común), I PCG (artículo 85.4 c).

En cuanto a la prohibición de la desaparición forzada de personas ${ }^{27}$, se constata que se encuentra reconocida en instrumentos internacionales generales y universales sobre derechos humanos, en cuanto protegen la libertad y seguridad de las personas ${ }^{28}$; en los estatutos de los tribunales penales internacionales $^{29}$; y por cierto en instrumentos internacionales pertenecientes al $\mathrm{DIH}$ : la Declaración sobre la protección de todas las personas contra las desapariciones forzadas, la Convención interamericana sobre desaparición forzada de personas, la Convención Internacional para la protección de todas las personas contra las desapariciones forzadas.

\section{Reconocimiento jurisprudencial del carácter de ius cogens de las normas del DIH}

La jurisprudencia internacional ha sido reticente en el reconocimiento del ius cogens en sus decisiones. Esta cautela se debe al debate que genera la

ETPIR (art. $2^{\circ}$ ), ETPI (arts. $5^{\circ}, 6^{\circ}$ y 33). Destacable es su prohibición en el mundo árabe, lo cual ha quedado plasmado en la DCDHI art. 2.B.

22 Cfr. Puceiro (1974), p. 70; Gros (1981), p. 48; Gilbert (1990), p. 349; Drnas (2002), p. 15; Crawford (2004), pp. 232 y 293, Criddle y Fox-Decent (2009), p. 331, Lepard (2010), p. 249.

${ }^{23}$ Vid. Carta de las Naciones Unidas (art. 55.c), DUDH (arts. 1o, $2^{\circ}$ y $7^{\circ}$ ), PIDCP (arts. 20 y 26).

24 Vid. arts. 2 DADH, 24 CADH, 14 ConEDH, 21 CDFUE, 28 CAfDHP, 2 y 3 CArDH.

${ }^{25} \mathrm{Vid}$. Convención internacional sobre la represión y el castigo del crimen de apartheid y Convención internacional contra el apartheid en los deportes.

${ }^{26}$ Vid. ETMN (art. 6 c)), ETPIY (arts. 4 y 5), ETPIR (arts. $2^{\circ}$ y $3^{\circ}$ ), ETPI (art. 7 j j).

27 Vid. Orentlicher (1991), p. 2582; Criddle y Fox-Decent (2009), p. 331.

${ }^{28}$ Vid. arts. 3, 9 y 13 DUDH, 9 PIDCP y los siguientes tratados regionales sobre derechos humanos: DADH arts. $1^{\circ}$ y $25, \mathrm{CADH}$ arts. 7 y 22, ConEDH art. 5, CDFUE art. 5, CAfDHP arts. 6 y 12, y $\mathrm{CArDH}$ art. 14.

${ }^{29}$ Vid. ETMN (art. 6 c)), ETPIY (art. 5o), ETPIR (art. 3o), ETPI (art. $7^{\circ}$ i). 
institución, por ser un concepto abstracto y difuso, difícil de aprehender, de determinar en lo concreto, y de conseguir unanimidad de criterio entre los jueces respecto a sus características y consecuencias. Sin embargo, en la mayoría de los tribunales de justicia internacionales se encuentra el uso de la expresión, o se refieren a su concepto, sea en el voto de mayoría o en las opiniones separadas de los jueces ${ }^{30}$; la doctrina del ius cogens está presente y cumple su fin de ir paulatinamente asentando en la conciencia jurídica la importancia de los valores e intereses esenciales de la comunidad internacional.

En el Caso del Estrecho de Corfú (1949) resuelto por la CIJ, se discute el paso inocente de buques de guerra de Gran Bretaña por el Canal ante la presencia de minas supuestamente colocadas por Albania, se determina que el principio de la libertad de las comunicaciones maritimas y el derecho a paso inocente son normas obligatorias para los Estados por constituir consideraciones elementales de humanidad, absolutas, bajo cualquier circunstancia. Aunque ello aparezca recogido por escrito en la Convención VIII de La Haya, aplicable en tiempo de guerra, también el principio es de aplicación en tiempos de paz, por ser el principio un estándar mínimo internacional general de aplicación universal válido en toda circunstancia entre las naciones civilizadas. ${ }^{31}$

Luego, a propósito de la opinión consultiva formulada por la Asamblea General de las Naciones Unidas (AGONU), respecto a si las Reservas a la Convención para la Prevención y la Sanción del Delito de Genocidio(1951), excluían a los Estados reservatarios de la Convención por no estar las reservas aceptadas por el consentimiento unánime de todos los Estados firmantes, se destaca al crimen de genocidio como norma de ius cogens, al señalar la CIJ que este crimen conmueve la conciencia humana al implicar el rechazo del derecho a la existencia de grupos humanos enteros, inflige grandes pérdidas a la humanidad, y es contrario a la ley moral, siendo objetivos de la CPSDG salvaguardar la existencia misma de ciertos grupos humanos, por un lado, y confirmar y respaldar los principios de moralidad más elementales, por otro. $^{32}$

\footnotetext{
${ }^{30}$ Se destaca en este reconocimiento la Corte Internacional de Justicia, los Tribunales ad-hoc para la ex Yugoslavia y Ruanda, las Cortes Europea e Interamericana de Derechos Humanos.

${ }^{31}$ Corte Internacional de Justicia. The Corfu Channel Case, 9 de abril de 1949, p. 22.

${ }^{32}$ Corte Internacional de Justicia. Reservations to the Convention on the Prevention and Punishment of the Crime of Genocide, 28 de mayo de 1951, p. 23.
} 
En el asunto Barcelona Traction(1970) se mencionan como obligaciones de interés jurídico para toda la comunidad internacional aquellas que derivan de la prohibición de los actos de agresión y de genocidio, de los principios y reglas relativos a los derechos fundamentales de la persona humana incluida la protección contra la práctica de la esclavitud y de la discriminación racial. $^{33}$

Con posterioridad, en la opinión consultiva presentada por la AGONU a la CIJ Acerca de la licitud de la amenaza o empleo de las armas nucleares (1996) queda de manifiesto que los principios y normas del DIH, incluyendo aquellas que prohíben el uso de armas con efectos indiscriminados y que causan males superfluos, como las armas nucleares, forman parte del ius cogens, ello por el respeto que se debe a la persona humana y por consideraciones elementales de humanidad. Aunque la CIJ haya evitado referirse al ius cogens implícitamente alude al concepto al usar frases como "instransgredibles principios de derecho internacional consuetudinario". ${ }^{34}$

En esta Opinión Consultiva, también es posible encontrar a magistrados que individualmente afirman en forma explícita que las normas de derecho humanitario deben ser consideradas normas de ius cogens. Así, el juez BEDJAOUI declara que no duda en que la mayoría de los principios y reglas del derecho humanitario, incluyendo aquellos que prohíben el uso de armas de efectos indiscriminados y aquellas que causan sufrimientos innecesarios, forman parte del ius cogens. ${ }^{35}$ Por su parte, el juez Weeramantry, en su opinión disidente señala que las normas de derecho humanitario han adquirido carácter de ius cogens debido a su fundamentalidad, que su derogación no es posible, porque se negarían las consideraciones básicas de humanidad que intentan proteger. En este contexto declara que el uso de armas nucleares es una prohibición de ius cogens. ${ }^{36}$

Sin perjuicio que los principios básicos del derecho internacional humanitario son de reconocido estatus de ius cogens, lo cual se recoge principalmente en el artículo $3^{\circ}$ común a los Convenios de Ginebra, existen otros instrumentos

\footnotetext{
${ }_{33}$ Corte Internacional de Justicia. Barcelona Traction, Light and Power Company, Limited (Belgium v. Spain) (New Application: 1962), 5 de febrero de 1970, párs. 33 y 34.

${ }^{34}$ Corte Internacional de Justicia. Legality of the Threat or Use of Nuclear Weapons, 8 de julio de 1996, pár. 79.

35 Ídem., pár. 21 voto separado del juez Bedjaoui.

36 Ídem., apartado 10 de la opinión disidente del juez WeEramantry.
} 
de DIH, la CIJ, en la opinión consultiva acerca de la construcción de una pared en territorio palestino, hace alusión al Cuarto Convenio de la Haya de 1907, en razón que aunque no haya sido ratificado por Israel es aplicable al caso, pues las reglas generales de costumbre de la guerra son parte del derecho internacional consuetudinario. ${ }^{37}$

Por su parte los Tribunales penales internacionales ad hoc, para Ruanda y para la ex Yugoslavia, reconocen las normas de ius cogens en el ámbito del DIH, en especial respecto de los crímenes de lesa humanidad. Así, v.g. el genocidio es reconocido en los casos en contra de Kayishema (1999) ${ }^{38}$, Jelisic (1999) ${ }^{39}$, Kupreskic (2000) $)^{40}$, Krstic (2001) $)^{41}$, Stakic (2003) ${ }^{42}$, Brdjanin (2004) ${ }^{43}$, Blagojevic $(2005)^{44}$, entre otros; y la tortura en, Delacic $(1998)^{45}$, Furundzija $(1998)^{46}$, Kunarac $(2001)^{47}$, Simic $(2002)^{48}$, Naletilic $(2003)^{49}$, entre otros.

${ }^{37}$ Corte Internacional de Justicia. Legal Consequences of the Construction of a Wall in the Occupied Palestinian Territory, 9 de julio de 2004, pár. 89.

38 Tribunal Penal Internacional para Ruanda, Casos Nos. ICTR-95-1-T, 21 de mayo de 1999, pár. 88.

39 Tribunal Penal Internacional para la ex Yugoslavia, Caso No IT-95-10, 14 de diciembre de 1999, pár. 60.

40 Tribunal Penal Internacional para la ex Yugoslavia, Caso nºIT-95-16-T,14 de enero de 2000, pár. 520.

${ }^{41}$ Tribunal Penal Internacional para la ex Yugoslavia, Caso No IT-98-33, 2 de agosto de 2001, pár. 541.

${ }^{42}$ Tribunal Penal Internacional para la ex Yugoslavia, Caso No IT-97-24-T, 31 de julio de 2003, pár. 500.

43 Tribunal Penal Internacional para la ex Yugoslavia, Caso No IT-99-36, 1 de septiembre de 2004, pár. 680.

${ }_{44}$ Tribunal Penal Internacional para la ex Yugoslavia, Caso No IT-02-60, 17 de enero de 2005, pár. 639.

45 Tribunal Penal Internacional para la ex Yugoslavia, Caso No IT-96-21-T, 16 de noviembre de 1998, pár. 454.

46 Tribunal Penal Internacional para la ex Yugoslavia, Caso No IT-95-17/1-T, 10 de diciembre de 1998, pár. 144, 153-157.

${ }_{47}$ Tribunal Penal Internacional para la ex Yugoslavia, Casos Nos. IT-96-23-T and IT-96-23/1, 22 de febrero de 2001, pár. 466.

48 Tribunal Penal Internacional para la ex Yugoslavia, Caso No IT-95-9/2-S, 17 de octubre de 2002, pár. 34.

49 Tribunal Penal Internacional para la ex Yugoslavia, Caso No IT-98-34, 30 de marzo de 2003, pár. 336. 
En el sistema regional europeo de protección de los derechos humanos, se destaca en la Corte Europea de Derechos Humanos, el reconocimiento y de los crimenes internacionales de lesa humanidad, en especial, de la tortura ${ }^{50}$, del genocidio $^{51}$, y del apartheid ${ }^{52}$.

En el ámbito americano, en el seno de la $\mathrm{CtIDH}$, se ha afirmado que la Cláusula Martens es fuente del derecho internacional general, y que las leyes de humanidad y las exigencias de la conciencia pública invocadas en base a esta cláusula pertenecen al dominio del ius cogens, concretizando más aún aquella afirmación que reconoce al DIH como integrante del plexo de normas de ius cogens. ${ }^{53}$ También reconoce el carácter de ius cogens de los principios fundamentales del Derecho Internacional Humanitario. ${ }^{54}$

A nivel de jurisdicción interna, paulatinamente durante las dos últimas décadas, se ha ido reconociendo la existencia del ius cogens y se ha ido incorporando en sentencias nacionales de países latinoamericanos.

De entre ellos, Colombia destaca como uno de los Estados mayormente comprometidos en su práctica jurisprudencial con el ius cogens y, por cierto, su Corte Constitucional reconoce el carácter de ius cogens de las normas y principios del Derecho Internacional Humanitario, refiriéndose en extenso en uno de sus fallos al carácter de ius cogens de algunos principios específicos, tales como el principio de distinción (entre combatientes y no combatientes, en aras de la

\footnotetext{
${ }^{50}$ Vid. v.g. las sentencias de los siguientes casos de la Corte Europea de Derechos Humanos, Al-Adsaniv. The United Kingdom, 21 de noviembre de 2001, párs. 57-61; Demirand Baykara v. Turkey, 12 de noviembre de 2008, pár. 73; Opuzv. Turkey, 9 de junio de 2009, pár. 125;Othman (Abu Qatada) v. The United Kingdom, 17 de enero de 2012, pár. 266.

${ }^{51}$ Vid. v.g. Corte Europea de Derechos Humanos. Jorgic v. Germany, 12 de julio de 2007, pár. 68.

52 Vid. v.g. Comisión Europea de Derechos Humanos. Cyprus v. Turkey, 4 de junio de 1999, pár. 93; y Corte Europea de Derechos Humanos, Xenides-Arestis Xenides-Arestis v. Turkey, 2 de septiembre de 2004, p. 29.

53 Vid. votos separados del juez CANÇADO en Corte Interamericana de Derechos Humanos, Caso Barrios Altos vs. Perú, 14 de marzo de 2001, Serie C No 75, pár. 25; Opinión Consultiva sobre la Condición Jurídica y Derechos de los Migrantes Indocumentados, 17 de septiembre de 2003, Serie A No 18, pár. 29; Caso Masacre Plan de Sánchez vs. Guatemala, 29 de abril de 2004, Serie C No 105, párs. 12, 21 y 22.

${ }^{54}$ Cfr. votos del juez CANÇADO en la Corte Interamericana de Derechos Humanos, Caso Blake vs. Guatemala, 24 de enero de 1998, Serie C No 36, pár. 15; Opinión Consultiva sobre la Condición Jurídica y Derechos de los Migrantes Indocumentados, 17 de septiembre de 2003, Serie A No 18, pár. 29; y Caso de las Hermanas Serrano Cruz vs. El Salvador, 23 de noviembre de 2004, Serie C No 118, pár. 40, Caso Del Penal Miguel Castro Castro vs. Perú, 2 de agosto de 2008, Serie C No 181, pár. 154. También vid. Caso De la Masacre de las Dos Erres vs. Guatemala, 24 de noviembre de 2009, Serie C No 211, pár. 1 c) del voto razonado concurrente del juez ad hoc CADENA.
} 
protección de la población civil, en todo tipo de conflicto armado), el principio de precaución (tomar todas las precauciones factibles para evitar, o reducir al mínimo, daños a la población civil, que pudieran causar incidentalmente) y el principio de trato humanitario y respeto por las garantías fundamentales (que protege el bien jurídico de la dignidad humana fundamento último del DIH como un todo). ${ }^{55}$

Por su parte, en los tribunales de justicia chilenos, es posible identificar fallos de la Corte de Apelaciones de Santiago ${ }^{56}$, votos disidentes de ministros de la Corte Suprema ${ }^{57}$, y votos de mayoría de dicha Corte ${ }^{58}$, que han utilizado normas de ius cogens del DIH para fundamentar la imprescriptibilidad de los crímenes de lesa humanidad y las acciones reparatorias que surgen de tales delitos.

\section{EL APORTE DE LAS NORMAS DE IUS COGENS DEL DIH A LA PROTECCIÓN DE LOS DERECHOS FUNDAMENTALES}

El hecho de que la mayoría de los conflictos armados contemporáneos sean conflictos internos ha acentuado la influencia del DIDH en el DIH, ya que en estos conflictos ambos sistemas normativos desempeñan un papel de igual importancia, sobre todo considerando que la mayoría de las violaciones graves del DIH son también violaciones de los Derechos Humanos. Los ámbitos de aplicación de estos ordenamientos están claramente separados, pero hoy, a menudo, son aplicables simultánea y paralelamente, de manera acumulativa, en caso de conflictos bélicos internos. Creemos que esta aplicación simultánea también se puede realizar en tiempos de paz, tratándose de normas que gozan

\footnotetext{
${ }^{55}$ Especialmente en relación al art. $3^{\circ}$ común a los CG. Vid. v.g. los siguientes fallos de la Corte Constitucional colombiana: sentencia No C-534/08, 28 de mayo de 2008, pár. 4.1.3.5; sentencia No C-695/02, 28 de agosto de 2002, aclaración de voto, fundamento 12; sentencia No C-177/01, 14 de febrero de 2001, pár. 3; sentencia No C-225/95, 18 de mayo de 1995, pár. 7.

${ }^{56}$ Vid. v.g. sentencias de la Corte de Apelaciones de Santiago: Rol No 37483-2004, 18 de enero de 2006, considerando 15; Rol No 14058-2004, 27 de junio de 2006, considerando 33º; Rol No 5937-2006, 8 de noviembre de 2006, considerando $8^{\circ}$; Rol № 14281-2006, 2 de agosto de 2007, considerando $8^{\circ}$; Rol No 11801-2006, 18 de diciembre de 2007, considerando 4º; Rol № 1579-2007,18 de diciembre de 2007, considerando 17.

${ }^{57}$ Vid. v.g. Corte Suprema, Rol No 6458-2008, 14 de diciembre de 2010, considerando $21^{\circ}$ del voto en contra del Ministro Sr. MuŃoz.

${ }^{58}$ Vid. v.g. sentencias de la Corte Suprema: Rol No 6188-2006, 13 de noviembre de 2007, considerando $29^{\circ}$ de la sentencia de reemplazo; Rol No 696-2008, 25 de mayo de 2009, considerandos $9^{\circ}$ a $11^{\circ}$ y 22 de la sentencia de reemplazo; Rol No 4662-2007, 25 de septiembre de 2008, considerando $8^{\circ}$ de la sentencia de reemplazo.
} 
de la categoría de ius cogens, pues ello permite garantizar de una manera más completa y amplia los derechos de las personas.

Por ejemplo, el principio fundamental del DIH es el de humanidad, el cual consagra la necesidad de un mínimo de trato humanitario ${ }^{59}$, y que se encuentra plasmado en el artículo $3^{\circ}$ común a los cuatro CG, protegiendo la vida y la integridad física y psíquica de la persona, sin discriminación, al prohibir una serie de actos: el homicidio, en todas sus formas; las mutilaciones; los tratos crueles, torturas y suplicios, la toma de rehenes, los tratos humillantes y degradantes; $y$, las condenas dictadas y las ejecuciones efectuadas sin previo juicio, emitido por un tribunal regularmente constituido, provisto de garantías judiciales. Este parámetro mínimo de humanidad coincide en gran parte con el denominado núcleo duro de los Derechos Humanos. ${ }^{60}$

Este artículo $3^{\circ}$ común se refiere a normas humanitarias de naturaleza tan fundamental que sin temor a equivocarse puede decirse son verdaderas normas de ius cogens, cuya derogación no es posible en ninguna circunstancia y cuya aplicación va más allá de cualquier vínculo convencional existente. ${ }^{61}$ Por tanto esta norma de DIH es aplicable también en caso de violaciones a los derechos fundamentales de la persona en tiempos de paz, pues las normas de ius cogens son generales, universales e imperativas. Evocamos a figuras tales

\footnotetext{
59 Cfr. Pictet (1986), p. 77; Droege (2007), pp. 1 y 2.

${ }^{60}$ Núcleo que indica los derechos humanos fundamentales e imperativos, los cuales se pueden descubrir al identificar aquellos derechos que no pueden suspenderse durante estados de excepción o emergencia. En el ámbito de la jurisprudencia nacional americana, se destaca la colombiana que reconoce que el DIH coincide con el núcleo duro de los derechos humanos, cfr. v.g. sentencias de la Corte Constitucional colombiana No C-177/01, 14 de febrero de 2001, apartado VI sobre consideraciones y fundamentos del fallo, y No C-534/08, 28 de mayo de 2008, acápite V sobre las consideraciones de la Corte.

Por su parte en Venezuela, se ha afirmado que este núcleo esencial de derechos humanos intangibles inderogables, que constituirían una especie de ius cogens mantienen plena vigencia, incluso bajo regímenes de excepción, vid. v.g. Tribunal Supremo de Justicia de Venezuela, expediente No 00-1401, 5 de junio de 2003, pár. b.1 del apartado III sobre consideraciones para decidir de la Corte.

${ }^{61}$ Cfr. Sinclair (1973), pp. 123 y 124; Gowlland(1994), p. 93; Crawford (2004), p. 294; Kadelbach (2006), pp. 30 y 31; Shelton (2006), p. 303; pár. 7 de los fundamentos jurídicos de la sentencia de la Corte Constitucional colombiana, No C-225/95, 18 de mayo de 2005; Corte Interamericana de Derechos Humanos, Caso Barrios Altos vs. Perú, 14 de marzo de 2001, Serie C No 75, voto concurrente del juez CANÇADO, pár. 25; Voto concurrente del mismo juez en Opinión Consultiva de la Corte Interamericana de Derechos Humanos, Opinión Consultiva sobre la Condición Jurídica y Derechos de los Migrantes Indocumentados, 17 de septiembre de 2003, Serie A No 18, pár. 29. Recordemos que la Corte Internacional de Justicia, en Case concerning Military and Paramilitary Activities in and against Nicaragua (Nicaragua v. United States of America), 27 de junio de 1986, pár. 218, se pronunció a favor de la existencia de reglas de DIH que constituyen "consideraciones elementales de humanidad".
} 
como el genocidio, la tortura, la desaparición forzada de personas, los tratos crueles, inhumanos o degradantes, las ejecuciones sumarias, en general a toda conducta catalogable como crimen de lesa humanidad, actuaciones que se encuentran prohibidas en forma perentoria para todos los Estados y cuya realización no sólo provoca la obligación por parte de la comunidad internacional de su repudio, sino también obliga a su persecución y castigo, tomando en consideración los efectos o consecuencias que generan las características de este tipo de normas, es decir su inderogabilidad, imprescriptibilidad e inamnistiabilidad, y el surgimiento de obligaciones erga omnes, jurisdicción universal y responsabilidad internacional agravada.

Por tanto, si los jueces consideraran que ciertas violaciones de derechos fundamentales en tiempos de paz quedan subsumidas en el catálogo del artículo $3^{\circ}$ común a los CG y reconocieran su carácter de ius cogens, obtendrían un mayor aseguramiento de la debida satisfacción de las víctimas de estas oprobiosas conductas, pues mientras los mecanismos establecidos para asegurar los derechos fundamentales en el DIDH esencialmente se orientan hacia las acciones de reparación de los perjuicios sufridos, los efectos de las normas de ius cogens apuntan más bien a la prevención de la impunidad de los actos.

\section{Obligaciones anejas a la responsabilidad internacional agravada que surge de la vulneración de las normas de ius cogens}

El documento internacional en materia de responsabilidad internacional del Estado, redactado en el seno de la Comisión de Derecho Internacional, titulado Artículos sobre Responsabilidad del Estado por Hechos Internacionalmente Ilícitos indica que no cabe el reconocimiento de circunstancias que excluyen la ilicitud tales como el consentimiento, la legítima defensa, las contramedidas, la fuerza mayor, el peligro extremo o el estado de necesidad, tratándose de hechos contrarios a las obligaciones que emanan de una norma de ius cogens. ${ }^{62}$ Así, v.g. por no admitirse el consentimiento, un individuo protegido por la norma de ius cogens que prohíbe la tortura no se puede renunciar a tal protección y consentir en tal atentado contra la integridad física y sicológica; por su parte, el Estado que adopte contramedidas no puede apartarse del cumplimiento de las normas de ius cogens, por tanto un genocidio no justificaría otro genocidio.

${ }^{62}$ Vid. Art. 26 del documento en comento. Cfr. CraWford (2004), p. 231. 
Además, en caso de graves violaciones a normas de ius cogens, se generan consecuencias adicionales ${ }^{63}$ respecto de las que surgen a propósito de cualquier incumplimiento de obligaciones internacionales ${ }^{64}$, las que se establecen en el artículo 41 del documento en análisis: $1^{\circ}$ Deber de protección. Los Estados deben cooperar para poner fin a la violación a través de medios lícitos; y $2^{\circ}$ Deber de abstención. Los Estados no pueden reconocer como lícitas este tipo de violaciones, y menos prestar ayuda o asistencia para mantenerla.

Otro aspecto de este documento que permite enfatizar el afán de no dejar impunes los actos que violan normas de ius cogens, entre ellas las infracciones graves previstas en el artículo $3^{\circ}$ común a los cuatro CG, se relaciona con la pretensión de jurisdicción universal para la persecución y el castigo de los crímenes de lesa humanidad, en cuanto conforme al artículo 48 del documento, cualquier Estado, aunque no sea el directamente lesionado con la violación, puede invocar la responsabilidad del Estado infractor. ${ }^{65}$ Esta idea se concreta en los CG: "[c]ada una de las Partes Contratantes tendrá la obligación de buscar a las personas acusadas de haber cometido, u ordenado cometer, una cualquiera de las infracciones graves, y deberá hacerlas comparecer ante los propios tribunales, sea cual fuere su nacionalidad. Podrá también, si lo prefiere, y según las disposiciones previstas en la propia legislación, entregarlas para que sean juzgadas por otra Parte Contratante interesada, si ésta ha formulado contra ellas cargos suficientes". ${ }^{66}$

Asimismo, los CG, expresamente impiden la exoneración de responsabi$\operatorname{lidad}^{67}$, por lo que a través de una interpretación finalista podríamos aseverar que tratándose de infracciones graves a la dignidad humana o crímenes de

${ }^{63}$ Como enfatiza Crawford (2004), p. 292, estas consecuencias adicionales se generan no sólo para el Estado responsable o afectado, sino para todos los demás Estados.

${ }^{64}$ Estas consecuencias adicionales se generan sin perjuicio de cualesquiera otras, es decir, al igual que cualquier violación de un hecho ilícito genera las consecuencias para el Estado responsable de cesar en el hecho ilícito, de cumplir con la obligación violada, de dar garantías de no repetición, y de dar reparación a los afectados; además, deja a salvo el desarrollo ulterior del régimen jurídico de las violaciones graves. Cfr. Crawford (2004), p. 300; Casado y Vásquez (2005), pp. 353 y 354.

${ }^{65}$ Cfr. Casado y Vásquez (2005), p. 350; Comité Internacional de la Croix-Rouge (1972), p. 22.

${ }^{66}$ Arts. 49 inciso $2^{\circ}$ I CG, 50 inciso $2^{\circ}$ II CG, 129 inciso $2^{\circ}$ III CG, 146 inciso 2o IV CG. Es menester destacar que las disposiciones que son objeto de arts. comunes de los cuatro Convenios tienen el valor de principios, pues estos arts. se aplican igualmente a las diferentes categorías de personas protegidas, por esta razón, han sido redactados en términos idénticos y son de carácter universal. Cfr. Cousier (1962), p. 25.

${ }^{67}$ Arts. 51 I CG, 52 II CG, 131 III CG, 148 IV CG. 
lesa humanidad, los Estados están impedidos jurídicamente de acoger causales de extinción de la responsabilidad tales como la amnistía o la prescripción, basados en la renuncia a su pretensión punitiva por razones políticas o de necesidad de paz social o de consolidación de las situaciones de hecho una vez transcurrido un tiempo determinado. Si bien estas medidas pudieran estar contempladas y reguladas en la legislación nacional, el ejercicio de las mismas debe ajustarse a los límites impuestos por el orden internacional. Se han de considerar las normas consuetudinarias del DIH, el carácter de ius cogens de ellas, y además el hecho de ratificación de los CG. La ley interna ha de interpretarse de manera tal que no resulte incompatible con las cláusulas de este tratado o los principios fundantes de las mismas de carácter de ius cogens.

\section{Obligación de armonizar la legislación nacional con la normativa internacional en materia de infracciones graves a la dignidad humana}

Otro indicador de que las normas del DIH se dirigen a evitar la impunidad de las infracciones graves a la dignidad humana en todo tiempo y lugar, son las disposiciones de los Convenios de Ginebra que exigen imperativamente a cada Estado Parte que dicte la normativa interna que sea necesaria para garantizar el cumplimiento de sus obligaciones internacionales ${ }^{68}$, por ejemplo, las infracciones graves al DIH descritas en el artículo $3^{\circ}$ de los CG y que podemos catalogar como crímenes de lesa humanidad -de tener ocasión en tiempos de paz-, deben convertirse en crímenes punibles según el derecho penal nacional, y de esta manera evitar la pugna que pudiera surgir entre los efectos de las normas de ius cogens y el principio de legalidad o tipicidad en derecho penal ${ }^{69}$.

En efecto, conforme al Capítulo IX del I CG, Capítulo VIII del II CG, ambos titulados de la Represión de los abusos y de las infracciones; Título VI, sección I del III CG; y, Título IV sección 1 $1^{\text {a }}$ del IV CG, "[l]as Altas Partes Contratantes se comprometen a tomar todas las oportunas medidas legislativas para determinar las adecuadas sanciones penales que se han de aplicar a las personas que hayan cometido, $o$ dado orden de cometer, una cualquiera de las infracciones graves" 70 siguientes:

\footnotetext{
${ }^{68}$ Cfr. Cousier (1962), p. 35.

69 De acuerdo a los dos incisos finales del art. 19 No 3 de la Constitución Política de la República vigente: "Ningún delito se castigará con otra pena que la que señale una ley promulgada con anterioridad a su perpetración, a menos que una nueva ley favorezca al afectado. / Ninguna ley podrá establecer penas sin que la conducta que se sanciona esté expresamente descrita en ella".

${ }^{70}$ Arts. 49 inciso $1^{\circ}$ I CG, 50 inciso $1^{\circ}$ II CG, 129 inciso $1^{\circ}$ III CG, 146 inciso $1^{\circ}$ IV CG.
} 
homicidio intencional, la tortura o los tratos inhumanos, incluidos los experimentos biológicos, el hecho de causar deliberadamente grandes sufrimientos o de atentar gravemente contra la integridad física o la salud, la destrucción y la apropiación de bienes, no justificada por necesidades militares y efectuadas a gran escala, ilícita y arbitrariamente, el hecho de forzar a un cautivo a servir en las fuerzas armadas de la Potencia enemiga o privarle de su derecho de ser juzgado regular e imparcialmente, las deportaciones y traslados ilegales, la detención ilegítima, y la toma de rehenes. ${ }^{71}$

Estas disposiciones erigen ante la conciencia internacional el cuadro de las infracciones graves, violaciones que, si quedasen sin castigo, significarían la degradación de la personalidad y la supresión del concepto de humanidad. ${ }^{72}$

Los Convenios disponen claramente que las infracciones graves han de ser castigadas, pero no establecen penas específicas ni un tribunal para juzgar a los infractores ${ }^{73}$. De ahí la importancia, por una parte, de crear los tipos penales correspondientes a nivel interno, adjudicándoles una pena determinada; y por otra, el reconocimiento de la jurisdicción universal.

Estos dos elementos son claves para garantizar la represión efectiva de las infracciones graves, pues en el caso de no existir el tipo penal acorde a la normativa internacional en el orden interno, ello no significa de manera alguna un abandono del castigo de quienes hayan cometido graves infracciones a la dignidad humana, el juzgador ante su deber de inexcusabilidad tendrá que encontrar una solución sirviéndose de las herramientas que su ordenamiento le provee, y por tanto tendrá que sancionar a quien estime culpable conforme a aquel tipo penal existente en el cual los hechos acaecidos puedan ser subsumidos. ${ }^{74}$ En todo caso, la jurisdicción internacional, operará de forma subsidiaria y complementaria, es decir, serán aplicables los tribunales internacionales a los

\footnotetext{
71 Arts. 50 I CG, 51 II CG, 130 III CG, 147 IV CG.

72 Cousier(1962), p. 35.

${ }^{73}$ Recordemos que conforme a los arts. 49 inciso $2^{\circ}$ I CG, 50 inciso $2^{\circ}$ II CG, 129 inciso $2^{\circ}$ III CG, 146 inciso $2^{\circ}$ IV CG, el derecho internacional humanitario impone a los Estados la obligación de buscar y castigar a todas las personas que hayan cometido infracciones graves, sin tener en cuenta la nacionalidad del infractor o el lugar donde se cometió el crimen

${ }^{74}$ La persecución penal de estos hechos puede lograrse a través del encuadramiento de las conductas en los tipos penales nacionales existentes y expresándose el mayor desvalor del injusto en el campo de la determinación de la pena al considerar la concurrencia de circunstancias agravantes, sin embargo, no se ha de olvidar su naturaleza de crímenes de lesa humanidad, por tanto a su respecto se han de aplicar las consecuencias aparejadas a la responsabilidad internacional agravada que con su ejecución se genera, entre ellas la imposibilidad de aplicación de causales de extinción de la responsabilidad penal
} 
cuales el Estado haya reconocido jurisdicción, y en última instancia cualquier tribunal nacional de un Estado extranjero que tenga creado el tipo penal correspondiente si empieza a conocer de los hechos criminales en virtud del principio de jurisdicción universal. ${ }^{75}$

\section{IMPLEMENTACIÓN EN EL ÁMBITO INTERNO DE LAS NORMAS DE IUS COGENS DEL DIH}

\section{Incorporación de las normas de ius cogens en el sistema jurídico chileno}

En materia de incorporación de las normas internacionales consuetudinarias, ya en el siglo XVIII, el Reino Unido consideraba que este tipo de normas del derecho internacional son per se parte del derecho del país, incorporándolo al orden interno por recepción automática a través de la costumbre judicial. ${ }^{76} \mathrm{En}$ el siglo XX, varios países, han introducido disposiciones constitucionales que consagran esta doctrina, y por tanto, incorporan el derecho internacional consuetudinario, a través de un mecanismo de recepción automática que tiene regulación constitucional expresa. ${ }^{77}$

previstas en la misma legislación nacional. Vid. ejemplos de cómo la judicatura nacional ha realizado esta aplicación en Díaz (2011a) pp. 68-72.

75 Considérese que el alcance y la forma de incorporación de este principio no son homogéneas en las legislaciones internas, algunas no especifican puntualmente los delitos a los cuales se aplica este principio, sino que su identificación se efectúa a través de una fórmula amplia, tal como la de "delitos contra el derecho de gentes" o "delitos contra el derecho internacional" o bien mediante una remisión a los delitos contemplados en los tratados internacionales de derechos humanos, otras consagran expresamente la aplicación del principio a crímenes internacionales precisos, por ejemplo, sólo respecto del genocidio.

El principio de justicia universal ampliamente concebido, en cuanto permite a cualquier jurisdicción interna perseguir y castigar crímenes de carácter de ius cogens sin atender a criterios de nacionalidad de la víctima o de sus autores, o del lugar de comisión de los actos, o de intereses particulares comprometidos del Estado persecutor, trajo una proliferación de denuncias en algunos tribunales nacionales, lo cual incitó a los legisladores locales a introducir criterios de restricción, v.g. vid. Ley belga relativa a las violaciones graves de derecho internacional humanitario promulgada el 5 de agosto de 2003.

${ }^{76}$ Aún hoy es válida en Inglaterra la doctrina del common law expuesta por BLACKSTONE en aquella concisa y admirable frase: "el derecho de gentes forma parte del derecho nacional". Los tribunales la han aplicado reiteradamente y nunca ha sido negado por los jueces. El primer precedente que se conoce en este sentido es el pronunciamiento del Lord Chancellor Talbot en el Caso Barbuit en 1737 el cual afirmó que el derecho de gentes en toda su extensión es y forma parte del derecho de Inglaterra. $C f$ r. Oppenheim (1966), p. 40; Miaja (1970), pp. 234 y 235; O'Connell (1970) p. 57; Akehurst (1972), pp. 77-80; Benadava (1992), p. 10; Mariño (1999), p. 527; Llanos (2011), p. 25.

77 Vid. v.g., el artículo 29.3 de la Constitución de Irlanda, del 1 julio de 1937:" Irlanda acepta los principios generalmente reconocidos del derecho internacional como regla de conducta en sus relaciones con los 
En Chile, la doctrina ${ }^{78}$, la jurisprudencia ${ }^{79}$ y la práctica gubernamental ${ }^{80}$ han reconocido la incorporación automática y global del derecho internacional general, de la costumbre internacional y de los principios generales del derecho desde los inicios de la República de manera sostenida y uniforme. ${ }^{81}$ En el siglo $\mathrm{XX}$, han existido intentos por hacer alusión a las normas del derecho internacional general o del derecho consuetudinario en la Constitución chilena ${ }^{82}$,

demás Estados"; el artículo 10 inciso 10 de la Constitución italiana, del 27 de diciembre de 1947: "El ordenamiento jurídico italiano se ajustara a las normas del derecho internacional generalmente reconocidas"; el artículo 25 de la Ley Fundamental de Bonn, de la entonces República Federal Alemana, del 23 de mayo de 1949: "Las reglas generales del Derecho Internacional forman parte integrante del Derecho Federal. Prevalecen sobre las leyes y hacen nacer derechos y obligaciones para los habitantes del territorio federal"; el artículo 7.1 de la Constitución de Hungría, del 20 de agosto de 1949: "El sistema jurídico de la República de Hungría acepta los principios generalmente reconocidos del derecho internacional, y armoniza la legislación nacional del pais a las obligaciones asumidas en virtud del derecho internacional"; el artículo 28.1 de la Constitución de Grecia, del 9 de junio de 1975: "Las normas de derecho internacional generalmente reconocidas, (...) serán parte integrante del derecho doméstico griego y prevalecerán sobre disposiciones jurídicas contrarias"; el artículo 8.1 de la Constitución de Portugal, del 2 de abril de 1976: "Las normas $y$ los principios de Derecho internacional, general o común, forman parte integrante de Derecho portugués"; el artículo 8 de la Constitución de Eslovenia, del 23 de diciembre de 1991: "Leyes y reglamentos deben ajustarse a los principios generalmente aceptados del derecho internacional (...)".En la región americana, la Constitución de Panamá de 11 de octubre de 1972, en su artículo $4^{\circ}$ establece que "La República de Panamá acata las normas del Derecho Internacional"; el artículo 149 de la Constitución de Guatemala de 31 de mayo de 1985 señala que "Guatemala normará sus relaciones con otros Estados, de conformidad con los principios, reglas y prácticas internacionales (...)”; el artículo 9 de la Constitución Colombia de 6 de julio de 1991, señala que "las relaciones exteriores del Estado se fundamentan en (...) el reconocimiento (revisar ver arts. 93 y 230) de los principios del derecho internacional"; el artículo 143 de la Constitución de Paraguay de 20 de junio de 1992 señala que "La República del Paraguay, en sus relaciones internacionales, acepta el derecho internacional (...)”; el artículo 26 de la Constitución de República Dominicana de 26 de enero de 2010 indica que "La República Dominicana es un Estado miembro de la comunidad internacional, abierto a la cooperación y apegado a las normas del derecho internacional (...)".

${ }^{78}$ Bello (1932), p. 52 sostiene ya en esa época que el derecho de gentes es parte del ordenamiento jurídico nacional.

79 Vid.v.g. Corte de Apelaciones de Santiago, Lechin y otros, 13 de julio de 1949 , considerando $9^{\circ}$ y Corte Suprema, Lauritzen y otros con Fisco, 19 de diciembre de 1955.

${ }^{80}$ V.g. BenadaVA (1992), pp. 18 y 19 alude a comunicación del Ministro de Relaciones Exteriores de Chile dirigida al Encargado de Negocios de Chile en Francia, y a dichos del Presidente de la República ante el Congreso Nacional, en el año 1833, que expresaban que el derecho internacional general se integran al ordenamiento jurídico chileno.

${ }^{81}$ Cfr. Precht (1967), p. 36; Bustos (1984), p. 526; Gaete (1996), pp. 265-269; Precht (1996), p. 385; Pfeffer (1997), p. 65; Nogueira (2000), p. 224; Montt (2005), p. 28; Vargas (2007), pp. 211-214; Llanos (2011), pp. 91-95.

${ }^{82}$ La Comisión de Estudio de la Nueva Constitución, en su oportunidad, consideró la posibilidad de incluir en el Preámbulo de la Constitución esta frase: "Chile adhiere a los principios y normas universal- 
pero en definitiva no prosperaron por considerarse que este tipo de normas internacionales ya se entendían de general aplicación, sólo se buscaba certeza jurídica, de manera tal que no hubiera duda alguna de que en Chile estas normas regían y regirían. ${ }^{83}$

De esta manera, se puede afirmar que las normas de ius cogens se incorporan de manera automática al ordenamiento jurídico chileno, pues siendo una subcategoría de normas de derecho internacional consuetudinario, es ese el mecanismo reconocido para esta categoría de normas del Derecho Internacional, en la doctrina y jurisprudencia chilenas.

No obstante, se ha de puntualizar que en la actualidad muchas normas de ius cogens se encuentran recogidas, plasmadas o cristalizadas en tratados internacionales ${ }^{84}$, por tanto en este caso, se incorporarían automáticamente al ordenamiento jurídico chileno por mandato constitucional expreso. Como fundamento de este aserto considérese que aunque la norma del artículo $5^{\circ}$ inciso $2^{\circ}$-que hace aplicables en el derecho interno los tratados internacionales, ratificados y vigentes en el país, que garanticen derechos esenciales que emanan de la naturaleza humana ${ }^{85}$, no indique explícitamente que exista una incorporación automática de estos instrumentos, ello es posible de desprender a través de una interpretación que considere no sólo este artículo de manera aislada, sino conjunta con el artículo $54 \mathrm{~N}^{\circ} 1$ de la misma Carta, en especial incisos $1^{\circ}$ y $5^{\circ}$, en los cuales el constituyente denota la voluntad de no transformar la norma internacional en interna, sino de respetar en todo momento la naturaleza de

mente aceptados del Derecho Internacional" (Cfr. Actas Oficiales de la Comisión de Estudio de la Nueva Constitución, sesión No 48, p. 1020, t. I). Luego, al discutirse la Reforma Constitucional de 1989 se planteó incluir la incorporación automática del derecho internacional consuetudinario a nuestro sistema jurídico, con la propuesta de esta redacción para el actual artículo 5 inciso $2^{\circ}$ de la Constitución: "Es deber de los órganos del Estado respetar y promover tales derechos, garantizados por esta Constitución y por las normas internacionales que comprometan a Chile". Cfr. CumpLido (1996), pp. 255-257; InFANTE (1996), pp. 279 y 280; Precht (1996), p. 386; Téllez (1998), p. 186.

83 Cumplido (2003), pp. 367 y 368; Campusano (2006), p. 39, n. 36.

${ }^{84}$ V.g. en materia de DIH, es posible encontrar normas de ius cogens plasmadas en los cuatro Convenios de Ginebra (1949) y sus dos Protocolos Adicionales (1977).

${ }^{85}$ Cabe hacer notar, que en la Comisión Técnica -que propone el texto de la Reforma Constitucional de 1989, que incorpora el inciso $2^{\circ}$ al art. $5^{\circ}-$, se discutió acerca de la alusión expresa de la incorporación de las normas de ius cogens, lo cual se consideró innecesario Cfr. Pinochet (1990), p. 11; Nogueira (1993), p. 57; Medina (1994), pp. 41 y 42; Bertelsen (1996), p. 221; Infante (1996), pp. 279 y 280; Nogueira (1996), p. 351; Precht (1996), p. 386; Cea (1997), p. 84; Ríos (1997), p. 102; Téllez (1998), p. 186, Cumplido (2003), p. 366; Pfeffer (2003), p. 478. 
la norma internacional y su calidad de tal, descartándose consecuentemente la incorporación vía transformación de la norma internacional en interna. ${ }^{86}$

Ahora, para que estas incorporaciones automáticas de las normas de ius cogens, en el sistema doméstico, tengan operatividad práctica, y que en definitiva puedan ser utilizadas por los tribunales nacionales en la resolución de los casos sometidos a su jurisdicción, se ha de tener en consideración la problemática en torno a la autoejecutabilidad de este tipo de normas ${ }^{87}$, pues las normas de protección de la persona humana frecuentemente requieren que sus principios sean llenados de contenidos, precisados, completados o detallados. De ahí que si el legislador no ha llevado a cabo la armonización del derecho interno con el internacional, si no ha creado las normas internas pertinentes adecuadas para dar fiel cumplimiento a los estándares de protección enunciados en el ámbito internacional, se vea dificultada la labor de aplicación inmediata de este tipo de normas por parte de los jueces.

Esta falta de operatividad también es posible de observar respecto de las normas internacionales del DIDH, por tanto he aquí una de las ventajas que se vislumbra de aplicar normas de ius cogens del DIH a los ámbitos de violación del DIDH, pues las primeras pueden ser útiles para precisar el contenido de las segundas, en caso necesario, aunque el ámbito propio de aplicación del DIH sean los conflictos armados.

\section{Aplicación de las normas de ius cogens del DIH por los tribunales de justicia chilenos}

Los tribunales chilenos han incorporados normas del DIH a la interpretación de violaciones de derechos humanos en el ámbito de los crímenes de lesa humanidad con estatus de ius cogens.

\footnotetext{
${ }^{86}$ En la Reforma Constitucional del año 2005, se intercaló en el inciso $1^{\circ}$ la frase "en lo pertinente", dando a entender que el tratado no es una ley, sino que su tramitación "se someterá, en lo pertinente, a los trámites de una ley". Por su parte el inciso $5^{\circ}$ enfatiza la naturaleza jurídica de la norma internacional, pues se dispone que "las disposiciones de un tratado sólo podrán ser derogadas, modificadas o suspendidas en la forma prevista en los propios tratados o de acuerdo a las normas generales de derecho internacional". CEA (1997), p. 83, señala que el derecho internacional convencional se incorporó a la Carta Fundamental de 1980 por la reforma de 1989 en términos globales y automáticos. En el mismo sentido, Rossel (1997), p. 118, estima que el art. $5^{\circ}$ de la Constitución consagra la incorporación automática de los tratados una vez ratificados.

Para una perspectiva crítica respecto de la regulación constitucional chilena acerca de las relaciones entre el Derecho Internacional y el ordenamiento interno, vid. Díaz (2011b).

${ }^{87}$ Cfr. Montt (2005), pp. 29-36. Tribunal Constitucional, Rol No 309, 4 de agosto de 2000.
} 
Para ello aluden al artículo $3^{\circ}$ común a los cuatro CG, y a las normas emanadas del derecho consuetudinario de ius cogens, así como a los principios generales de derecho internacional humanitario. ${ }^{88}$

Aseveran que los principios del derecho internacional y las reglas del derecho consuetudinario, forman parte del ordenamiento jurídico chileno, con primacía sobre las leyes internas, aun cuando no se encuentren traducidos en tratados o convenciones obligatorias para Chile. $\mathrm{Al}$ respecto, precisan que si bien la Convención sobre la imprescriptibilidad de los crimenes de guerra y los crimenes de lesa humanidad no se encuentra incorporada a nuestro ordenamiento jurídico como tal, confirma la existencia de un principio de ius cogens ya instalado en la costumbre internacional. Las normas de derecho internacional humanitario, como parte integrante del ius cogens, son obligatorias para los Estados, incluso cuando no se encuentran aprobados los respectivos tratados, desde que su fuerza emana de su carácter consuetudinario. ${ }^{89}$

Sin perjuicio de esto, la Corte no ha visto impedimento de DIH o de ius cogens para aplicar la prescripción como atenuante para mitigar la responsabilidad penal, aplicando la llamada media prescripción, o prescripción gradual o incompleta. ${ }^{90}$

\section{CONClusiones}

1. Las normas imperativas de derecho internacional general (ius cogens) no sólo se circunscriben a una especial causal de nulidad de los tratados (ámbito del Derecho de los Tratados), sino por desarrollo doctrinal y jurisprudencial se desarrolla y se aplica también en otros sectores del DIP; uno de ellos es el DIH.

\footnotetext{
88 Vid. v.g. Corte de Apelaciones de Santiago, Rol No 37483-2004, 18 de enero de 2006, considerando 15; Corte de Apelaciones de Santiago, Rol No 14058-2004, 27 de junio de 2006, considerando 33º Corte de Apelaciones de Santiago, Rol No 14281-2006, 2 de agosto de 2007, considerando 8º Corte de Apelaciones de Santiago, Rol No 1579-2007, 18 de diciembre de 2007, considerando 17o; Corte de Apelaciones de Santiago, Rol No 5937-2006, 8 de noviembre de 2006, considerando 8º; Corte Suprema, Rol No 4662-2007, 25 de septiembre de 2008, considerando $8^{\circ}$ de la sentencia de reemplazo.

89 Vid. v.g. Corte Suprema, Rol No 6188-2006, 13 de noviembre de 2007, considerando 29o de la sentencia de reemplazo; Corte Suprema, Rol No 696-2008, 25 de mayo de 2009, considerandos $9^{\circ}$ a $11^{\circ}$ de la sentencia de reemplazo.

90 Vid. v.g. Corte Suprema, Rol No 696-2008, 25 de mayo de 2009, considerando 22 de la sentencia de reemplazo.
} 
A fines del siglo XX y comienzos del XXI, las normas de ius cogens se perciben como una categoría especial de preceptos del DIP tan fundamentales y respecto de los cuales existe un reconocimiento o aceptación por parte de las naciones civilizadas en su conjunto, que las hacen imperativas, generales, universales, y prevalentes de frente a otras normas internacionales que no tengan este carácter o con normas internas o cualquier otro acto o acuerdo contrarias a ellas, sean fuentes nacionales o internacionales.

La doctrina y la jurisprudencia internacionales han reconocido el carácter de ius cogens de ciertas normas del $\mathrm{DIH}$, en especial del artículo $3^{\circ}$ común a los cuatro CG y de los crímenes de lesa humanidad, tales como la tortura, el genocidio, el apartheid y la desaparición forzada de personas.

2. Las normas del DIH, propio de los conflictos armados, pueden ser aplicadas en juicios ante los tribunales domésticos, en casos de vulneración de derechos fundamentales acaecidos en tiempos de paz, pues si bien la aplicabilidad del DIH exige la existencia de un conflicto armado, muchas de sus normas y principios consuetudinarios gozan de carácter de ius cogens, el cual por ser general, universal e imperativo es aplicable en todo tiempo y lugar y bajo cualquier circunstancia.

DIH y DIDH, aunque ramas autónomas del DIP, con aplicaciones en ámbitos específicos, y con órganos independientes entre sí, están íntimamente vinculadas, constituyendo distintas dimensiones de un mismo fenómeno, que persigue la protección de los derechos fundamentales de las personas bajo cualquier circunstancia, tiempo o lugar.

La esencia de todo el cuerpo normativo del DIH y del DIDH descansa en la protección de la dignidad humana de cada persona, independientemente de su género. El principio general de respeto de la dignidad humana es el pilar básico y la razón de ser de esta normativa. Este principio intenta proteger a los seres humanos de ultrajes sobre su dignidad personal.

Si las Naciones Unidas han afirmado la aplicabilidad de las normas del DIDH al DIH, tomando en consideración la dignidad humana como bien jurídico protegido, perfectamente se puede aplicar también a la inversa, es decir, normas del DIH en esferas propias del DIDH, en base al mismo fundamento.

Es necesario precisar, que en todo caso, que parece inoficioso distinguir entre DIH y DIDH tratándose de normas con carácter de ius cogens, pues tendencias ni separatistas ni de complementariedad entre DIH y DIDH explican en realidad el fenómeno que se produce respecto de las normas perentorias del 
derecho internacional general. En materia de normas de reconocida pertenencia al ámbito del ius cogens internacional estamos de frente a una verdadera integración del DIH y el DIDH en aras de la plena protección de la dignidad humana, lo cual es por lo demás coincidente con la vocación de universalidad del ius cogens.

3. El principal aporte complementario que realizan las normas de ius cogens del DIH a las violaciones de derechos fundamentales en tiempos de paz consiste en la búsqueda, a través de diversos mecanismos, de la persecución y castigo de los responsables de la comisión de infracciones graves a la dignidad humana-las mismas que pueden circunscribirse en el campo del derecho penal internacional en la nomenclatura de crímenes de lesa humanidad-.

Se aspira a abandonar toda impunidad respecto de estos hechos a través de una serie de obligaciones internacionales dirigidas a todos los Estados de la comunidad internacional y que coadyuvan a la progresiva y constante garantía de los derechos de la persona humana.

Entre estas obligaciones cabe destacar aquellas que se originan en virtud de la responsabilidad internacional agravada que acarrea la vulneración de normas imperativas de derecho internacional general, y el mandamiento incluido en los CG de tipificar en las legislaciones nacionales los crímenes que surgen de las infracciones graves a la dignidad humana.

4. La ventaja que se vislumbra de aplicar normas del DIH a las violaciones de derechos humanos en tiempo de paz, a propósito de la implementación que han dado los jueces chilenos en el ámbito interno, consiste en el reconocimiento en la práctica del principio pro homine, en cuanto deben prevalecer los argumentos sustantivos -en relación a los bienes jurídicos protegidos, especialmente, la dignidad humana- por sobre los aspectos procesales.

En concreto, no serían aplicables en el ámbito interno de los Estados instituciones procesales como la prescripción o la amnistía en caso de actos graves que infringen el artículo $3^{\circ}$ común de los CG, aunque los crímenes hayan acaecido en tiempos de paz y no de guerra.

\section{Bibliografía Citada}

Barberis, Julio A. (1970): "La liberté de traiter des Etats et le jus cogens", en Zeitschriftfür Auslandisches Offentliches Rechtund Volkerrecht, (vol. 30 No 1), pp. 19-45.

BASSIOUNI, M. Cherif(1996): "International crimes: jus cogens and obligatio erga omnes”, en Law and Contemporary Problems, (vol. 59 No 4), pp. 63-74. 
Bello, Andrés (1932): VI Obras Completas. Derecho Internacional (Santiago, Editorial Nascimento) $581 \mathrm{pp}$.

Belsky, Adam; Merva, Mark y Roht - Arriaza, Naomi (1989): "Implied waiver under the FSIA: a proposed exception of immunity for violations of peremptory norms of International Law", en California Law Review, (vol. 77 No 2), pp. 365-415.

BENADAVA, Santiago (1992): "Las relaciones entre derecho internacional y derecho interno ante los tribunales chilenos", en AA.VV., XXI Jornadas Chilenas de Derecho Público (Santiago, 1990). Nuevos enfoques del Derecho Internacional (Santiago, Editorial Jurídica de Chile), pp. 9-59.

(1997): Derecho Internacional Público (5ª edición, Santiago, Editorial Jurídica ConoSur), 377 pp.

Bertelsen Repetto, Raúl (1996): "Rango jurídico de los tratados internacionales en el derecho chileno", en Revista Chilena de Derecho,(vol. $23 \mathrm{No}^{\circ} .2$ y 3, Tomo I), pp. 211-222.

Bou Franch, Valentín (2002): "Inmunidad del Estado y violación de normas internacionales de juscogens: el asunto Al-Adsani contra Reino Unido", en Anuario de Derecho Internacional,(No 18), pp. 279-303.

BRownlie, Ian (2008): Principles of public international law (7ª edición, Oxford, Clarendon Press), 784 pp.

Bustos Valderrama, Crisólogo(1984): "La recepción del Derecho Internacional en el Derecho Constitucional chileno", en Revista Chilena de Derecho, (vol. 11 No 2-3), pp. 523-532.

(2000): "Los crímenes de Derecho Internacional y los conflictos armados no internacionales", en Revista de Derecho Consejo de Defensa del Estado, (No 2), pp. 143-166.

Caldeira Brant, Leonardo Nemer y Campos de Oliveira Soares, Larissa (2009): "A inter-relação entre direito internacional dos direitos humanos e o direito internacional huymanitáriona perspectiva universal e interamericana", en Anuario de Derecho Constitucional Latinoamericano, (año XV), pp. 603-619.

CAmpusano, Rafael F. (2006): "Tratados y el derecho internacional en la reforma constitucional de 2005", en Actualidad Jurídica, (No 13), pp. 25-41.

Casado Raigón, Rafael y Vásquez Gómez, Eva María (2005): "La impronta del ius cogens en el Proyecto de Artículos de la Comisión de Derecho Internacional sobre la Responsabilidad del Estado por Hechos Internacional- 
mente Ilícitos", en AA.VV., I Soberanía del Estado y Derecho Internacional. Homenaje al profesor Juan Antonio Carrillo Salcedo (Sevilla, Secretariado de Publicaciones Universidad de Sevilla), pp. 343-360.

Cea Egaña, José Luis (1997): "Los tratados de Derechos Humanos y la Constitución Política de la República”, en Ius et Praxis,(vol. 2 No 2), pp. 81-92.

Cohen, Harlan Grant (2007): "Finding International Law: Rethinking the Doctrine of Sources", en Iowa Law Review, (vol. 93), pp. 65-129.

Comité Internacional de la Croix-Rouge (1972): Comentario al programa de un curso sobre el Derecho Internacional Humanitario (Genéve, Comité Internacional de la Croix-Rouge), $46 \mathrm{pp}$.

Comité Internacional de la Cruz Roja (2007): "Introducción al derecho internacional humanitario", en Secretaría General de la OEA (editor), Curso Introductorio sobre Derecho Internacional Humanitario (Washington, OEA), pp. 25-55.

Cousier, Henri (1962): Curso de cinco lecciones sobre los Convenios de Ginebra (Ginebra, Comité Internacional de la Cruz Roja), 115 pp.

CraWford, James (2004): Los Artículos de la Comisión de Derecho Internacional sobre la Responsabilidad Internacional del Estado (Traducc. Luis FonsECA, Madrid, Dykinson), 461 pp.

Criddle, Evan J. and Fox-Decent, Evan (2009): "A Fiduciary Theory of Jus Cogens", en Yale Journal of International Law, (vol. 34 No 2), pp. 331-387.

Cumplido Cereceda, Francisco (1996): "Alcances de la modificación del artículo $5^{\circ}$ de la Constitución Política chilena en relación a los tratados internacionales", en Revista Chilena de Derecho,(vol. $23 \mathrm{No}^{\circ}$. 2 y 3, Tomo I), pp. 255-258.

(2003): "La reforma constitucional de 1989 al inciso $2^{\circ}$ del artículo $5^{\circ}$ de la Constitución: sentido y alcance de la reforma. Doctrina y Jurisprudencia”, en Ius et Praxis, (vol. 9 No 1), pp. 365-374.

DE WeT, Erika (2004): "The prohibition of torture as an international norm of jus cogens and its implications for national and customary law", en European Journal of International Law, (vol. 15 No 1), pp. 97-121.

Díaz Tolosa, Regina Ingrid (2006): "Aplicación de los Convenios de Ginebra por los tribunales de justicia chilenos", en Revista Chilena de Derecho, (vol. 33 No 2), pp. 305-327.

(2011a): "La implementación de las normas internacionales por parte de los poderes de Estado: La labor del Poder Judicial a falta de legislación penal armónica con la normativa internacional”, Ferrada Bórquez, Juan 
Carlos (coordinador), Estudios de Derecho Público (Santiago, LegalPublishing Chile) pp. 59-76.

(2011b): "Algunas consideraciones en materia de incorporación e interpretación de las normas internacionales en el ordenamiento jurídico chileno", Henríquez Viñas, Miriam (coordinadora), Perspectiva del Derecho Constitucional desde el mirador del Bicentenario (Santiago, Librotecnia) pp. 75-95.

Drnas de Clément, Zlata (2002): "La normas imperativas de Derecho Internacional general (JusCogens). Dimensión sustancial”, Estudios de Derecho Internacional en Homenaje al Profesor Ernesto J. Rey Caro (Córdoba, Drnas-Lerner Eds.) pp. 1 - 33, (fecha de consulta: 29 noviembre 2010). Disponible en: http://www.acaderc.org.ar/doctrina/articulos/ artiuscogens/?searchterm $=$ cogens

Droege, Cordula (2007): "El verdadero Leitmotiv: la prohibición de la tortura y otras formas de malos tratos en el derecho internacional humanitario", en Revista Internacional de la Cruz Roja,(No 867), pp. 1-29.

FERRARO, Romaric (2007): "La aplicación nacional del derecho internacional humanitario", en Secretaría General de la OEA (editor), Curso Introductorio sobre Derecho Internacional Humanitario (Washington, OEA) pp. 181-196.

ForD, Christopher A. (1994): "Adjudicating jus cogens", en Wisconsin International Law Journal, (vol. 13), pp. 145 - 181.

Fox, Donald (1988): "Current developments: Inter-American Commission on Human Rights finds United States in violation", en American Journal of International Law, (vol. 82 No 3), pp. 601-603.

GaEte GonzÁlez, Eugenio Alberto (1996): "Derecho Internacional y Derecho de los Estados. Incorporación de los Derechos Humanos", en Revista Chilena de Derecho (vol. 23 nos 2 y 3, Tomo I), pp. 259 - 275.

Gilbert, Geoff (1990): “The Criminal Responsibility of States", International and Comparative Law Quarterly, (vol. 39 No 2), pp. 345-369.

GonZÁlez Ramírez, Danilo (2007): "Normas básicas y principios fundamentales de protección a las personas en el derecho internacional humanitario", en Secretaría General de la OEA (editor), Curso Introductorio sobre Derecho Internacional Humanitario (Washington, OEA), pp. 89-168.

Gowlland Debbas, Vera (1994): "Security Council Enforcement Action and Issues of State Responsibility”, en International and Comparative Law Quarterly, (vol. 43 No 1), pp. 55-98. 
Gros Espiell, Héctor (1981): "No discriminación y libre determinación como normas imperativas de Derecho Internacional con especial referencia a los efectos de su denegación sobre la legitimidad de los Estados que violan o desconocen esas normas imperativas", en Anuario Hispano-Luso-Americano de Derecho Internacional, (No 6), pp. 33-81.

Henderson, Humberto (2004): "Los tratados internacionales de derechos humanos en el orden interno: la importancia del principio pro homine", en Revista Instituto Interamericano de Derechos Humanos, (vol. 39), pp. 38-99.

IguYovwe, Ruona (2008): "The Inter-play between International Humanitarian Law and International Human Rights Law”, en Commonwealth Law Bulletin,(vol. 34 No 4), pp. 749-789.

InFANTE CAFFi, María Teresa (1996): "Los tratados en el derecho interno chileno: el efecto de la Reforma Constitucional de 1989 visto por la jurisprudencia", en Revista Chilena de Derecho,(vol. 23 Nos. $^{2}$ y 3, Tomo I), pp. 277-297.

Kadelbach, Stefan (2006): "Jus cogens, Obligations Erga Omnes and other Rules - The Identification of Fundamental Norms", Tomuschat, Christian and Thouvenin, Jean-Marc (editors), The Fundamental Rules of the International Legal Order (Leiden, Martinus Nijhoff Publishers), pp. 21-40.

Kutz, Christopher (2007): “Torture, Necessity and Existential Politics", en California Law Review, (vol. 95 No 1), pp. 235-276.

LEPARD, Brian D. (2010): Customary International Law. A new theory with practical applications (New York, Cambridge University Press), 419 pp.

Lippman, Matthew (1979): "The Protection of Universal Human Rights: The Problem of Torture", en Universal Human Rights, (vol. 1 No 4), pp. 2555.

Llanos Mansilla, Hugo (2011): IV Teoría y Práctica del Derecho Internacional Público. Las relaciones entre el Derecho Internacional y el derecho interno (Santiago, Editorial Jurídica de Chile), 450 pp.

Mangas Martín, Araceli (1999): Conflictos armados internos y derecho internacional humanitario ( $2^{\text {a }}$ reimpresión $1^{\text {a }}$ edición 1990, Salamanca, Ediciones Universidad Salamanca), 193 pp.

Manili, Pablo Luis (2003) El bloque de constitucionalidad. La recepción del Derecho Internacional de los Derechos Humanos en el Derecho Constitucional argentino (Buenos Aires, La Ley), 377 pp.

McGregor, Lorna (2007): "Addressing the Relationship between State Immunity and Jus Cogens Norms: A Comparative Assessment”, KALECK, W., 
Ratner, M., Singelnstein, T., Weiss, P. (Eds.), International Prosecution of Human Rights Crimes (Berlin, Springer), pp. 69-84.

Meron, Theodor (1987): "The Geneva Conventions as Customary Law", en American Journal of International Law, (vol. 81 No 2), pp. 348-370.

Milanovic, Marko (2006): "State Responsibility for Genocide", en European Journal of International Law, (vol. 17), pp. 553-604.

Montt Oyarzún, Santiago (2005): “Aplicación de los tratados bilaterales de protección de inversiones por tribunales chilenos. Responsabilidad del Estado y expropiaciones regulatorias en un mundo crecientemente globalizado", en Revista Chilena de Derecho, (vol. 32 No 1), pp. 19-78.

Nogueira Alcalá, Humberto (1993): "Los derechos humanos en el derecho convencional internacional a la luz del artículo $5^{\circ}$ de la constitución chilena”, enCuadernos de análisis jurídico, (vol. 27), pp. 49-69.

(1996): "Los tratados internacionales en el ordenamiento jurídico chileno", en Revista Chilena de Derecho, (vol. $23 \mathrm{No}^{\circ} .2$ y 3, tomo I), pp. 341-380.

(2000): "Las Constituciones latinoamericanas, los tratados internacionales y los derechos humanos", en Anuario de Derecho Constitucional Latinoamericano, pp. 163-259.

Orakhelashvili, Alexander (2006): Peremptory norms in International Law (New York, Oxford University Press), 622 p.

OrentLICHER, Diane F. (1991): "The duty to prosecute human rights violations of a prior regime", en Yale Law Journal,(vol. 100 No 8), pp. 2537-2615.

PaUL, Vladimir (1971): "Legal consequences of conflict between a treaty an imperative norm of general international law (jus cogens)", en Osterreichische Zeitschriftfüröffentliches Recht, (vol. 21 No 1-2), pp. 19-49.

PAulus, Andreas L. (2005): "Jus cogens in a time of hegemony and fragmentation", en Nordic Journal of International Law, (vol. $74 \mathrm{No}^{\circ}$ s. 3-4), pp. 297-333.

Pfeffer Urquiaga, Emilio (1997): "Constitución Política de la República y tratados internacionales", en Ius et Praxis, (vol. 2 No 2), pp. 63-72.

(2003): "Los tratados internacionales sobre Derechos Humanos y su ubicación en el orden normativo interno", en Ius et Praxis, (vol. 9 No 1), pp. 467-484.

Pictet, Jean (1986): Desarrollo y principios del Derecho Internacional Humanitario (Ginebra, Instituto Henry Dunant), 113 pp. 
Pinochet ElorZa, César (1990): "Eficacia de la elevación a rango constitucional de los tratados internacionales sobre derechos humanos", en Cuadernos de Análisis Jurídico,(No 13), pp. 9-18.

Precht Pizarro, Jorge Enrique (1967): "Los tratados internacionales como fuentes del derecho administrativo. Incorporación global y automática de los tratados internacionales al derecho interno chileno", en Anales de la Facultad de Ciencias Jurídicas y Sociales cuarta época, (vol. 7 No 7), pp. 29-61.

(1996): "Vino nuevo en odres viejos: Derecho Internacional convencional y derecho interno chileno", en Revista Chilena de Derecho, (vol. $23 \mathrm{~N}^{\circ}$ s. 2 y 3, Tomo I), pp. 381-405.

Puceiro Ripoll, Roberto (1974): "Desarrollos actuales del jus cogens: El fantasma rompe su hechizo", en Revista Uruguaya de Derecho Internacional, (No 3), pp. 49-79.

RoberTs, Anthea Elizabeth (2001): "Traditional and modern approaches to customary international law: a reconciliation”, en American Journal of International Law, (vol. 95 No 4), pp. 757-791.

Rossel Contreras, Mario (1997): "Constitución y tratados de derechos humanos", en Ius et Praxis, (vol. 2 No 2), pp. 113-119.

SALMÓN, Elizabeth (2004): Introducción al Derecho Internacional Humanitario (Lima, Fondo Editorial de la Pontificia Universidad Católica del Perú y Comité Internacional de la Cruz Roja), 174 pp.

Santalla Vargas, Elizabeth (2007): "Convergencias y divergencias: derecho internacional de los derechos humanos, derecho internacional humanitario y derecho penal internacional con relación al conflicto armado", en Secretaría General de la OEA (editor), Curso Introductorio sobre Derecho Internacional Humanitario (Washington, OEA), pp. 57-66.

SCHEUner, Ulrich (1967): "Conflict of Treaty Provisions with a Peremptory Norm of General International Law (ius cogens) and its consequences. Comments on Arts. 50, 61 and 67”, en Zeitschriftfür Ausländisches Offentliches Recht und Völkerrecht, (vol. 27), pp. 521-532.

Schmahl, Stefanie (2006): "An example of jus cogens: The status of prisioners of war", Tomuschat, Christian and Thouvenin, Jean-Marc (editors), The Fundamental Rules of the International Legal Order (Leiden, MartinusNijhoff Publishers) pp. 41-67.

Shelton, Dinah (2006): "Normative hierarchy in International Law", en American Journal of International Law, (vol. 100 No 2), pp. 291-323. 
Sinclair, Ian Mac Taggart (1973): The Vienna Convention on the Law of Treaties (Manchester, University Press), 150 pp.

Téllez Soto, Claudia (1998): "Valor jurídico de los tratados internacionales en el derecho interno", en Revista de Derecho Universidad Austral, (vol. 9), pp. 179-190.

Troncoso Repetto, Claudio Marcelo (1988): "La norma del ius cogens aplicada a los derechos", en Derecho y sociedad: revista de ciencias sociales, (vol. 1 No 1$)$, pp. 72-84.

Tunkin, Grigory I. (1974): Theory of International Law (Trans. William E. Butler, London, George Allen \&Unwin Ltd.), 497 pp.

Verdross, Alfred (1937): "Forbidden Treaties in International Law: Comments on Professor Garner's Report on 'The Law of Treaties', en American Journal of International Law, (vol. 31 No 4), pp. 571-577.

Weisburd, Arthur (1995): "The emptiness of the concept of jus cogens. As illustrated by the war in Bosnia-Herzegovina", en Michigan Journal of International Law, (vol. 17), pp. 1-51.

Whiteman, Marjorie (1977): "Jus cogens in International Law, with a projected list", en Georgia Journal of International and Comparative Law, (vol. 7 No 2), pp. 609-626.

WiLson, John M. (2007): "El derecho internacional humanitario en el sistema interamericano", en Secretaría General de la OEA (editor), Curso Introductorio sobre Derecho Internacional Humanitario (Washington, OEA) pp. 67-87.

\section{Jurisprudencia Citada}

Case Oscar Chinn (Britain vs. Belgium) (1934): Sentencia, Corte Permanente de Justicia Internacional, 12 de diciembre de 1934, Series A/B No 63, (fecha de consulta: 28 de febrero de 2012).Disponible en http://www.worldcourts. $\mathrm{com} / \mathrm{pcij} / \mathrm{eng} / \mathrm{decisions} / 1934.12 .12 \_o s c a r \_c h i n n . h t m$

The Corfu Channel Case (United Kingdom of Great Britain and Northern Irelandv. Albania) (1949): Sentencia, Corte Internacional de Justicia, 9 de abril de 1949, (fecha consulta: 15 dejunio de 2010).Disponible en http:// www.icj-cij.org/docket/files/1/1645.pdf

Lechin y otros (1949): Corte de Apelaciones de Santiago, 13 de julio de 1949, recurso de amparo, en Gaceta de los Tribunales 1949, pp. 443 y 445. 
Lauritzen y otros con Fisco (1955): Corte Suprema, 19 de diciembre de 1955, en Revista de Derecho, jurisprudencia y Ciencias Sociales, tomo 52, 2a parte, seeción 1a, pp. 444 y ss.

Reservationsto the Conventionon the Prevention and Punishment of the Crime of Genocide (1951): Opinión Consultiva, Corte Internacional de Justicia, 28 de mayo de 1951, (fecha de consulta: 15 de junio de 2010). Disponible en http://www.icj-cij.org/docket/files/95/7495.pdf

Barcelona Traction, Light and Power Company, Limited (Belgiumv. Spain) (New Application: 1962) (1970): Sentencia, Corte Internacional de Justicia, 5 de febrero de 1970, (fecha de consulta: 15 de junio de 2010). Disponible en http://www.icj-cij.org/docket/files/50/5387.pdf

Case concerning Military and Paramilitary Activities in and against Nicaragua (Nicaragua v. United States of America) (1986): Sentencia, Corte Internacional de Justicia, 27 de junio de 1986, (fecha de consulta: 15 de junio de 2010). Disponible en http://www.icj-cij.org/docket/files/70/6503.pdf

Caso No 9647, Estados Unidos (1987): Informe No 3/87, Comisión Interamericana de Derechos Humanos, Reporte anual 1986-1987, (fecha de consulta: 15 de junio de 2010). Disponible en http://www.cidh.oas.org/annualrep/86.87sp/ EstadosUnidos9647.htm

Revisión de constitucionalidad del "Protocolo adicional a los Convenios de Ginebra del 12 de agosto de 1949, relativo a la protección de las victimas de los conflictos armados sin carácter internacional (Protocolo II)" hecho en Ginebra 8 de junio de 1977 (1995): Corte Constitucional colombiana, 18 de mayo de 1995, sentencia No C-225/95, (fecha de consulta: 2 de marzo de 2012). Disponible en el Sitio web de la Corte Constitucional colombiana, http:// www.corteconstitucional.gov.co/relatoria/1995/C-225-95.htm

Legality of the Threator Use of Nuclear Weapons(1996): Opinión Consultiva, Corte Internacional de Justicia, 8 de julio de 1996, (fecha de consulta: 15 de junio de 2010). Disponible en http://www.icj-cij.org/docket/files/95/7495.pdf

Case Prosecutor v. Delacic et al (1998): Sentencia, Tribunal Penal Internacional para la ex Yugoslavia, Caso No IT-96-21-T, 16 de noviembrede 1998, (fecha de consulta: 17 de junio de 2010).Disponible en http://www.icty.org/x/ cases/mucic/tjug/en/981116_judg_en.pdf

Case Prosecutor v. Furundzija(1998): Sentencia, Tribunal Penal Internacional para la ex Yugoslavia, Caso No IT-95-17/1-T, 10 de diciembre 1998, (fecha de consulta: 17 de junio de 2010).Disponible en < http://www.icty.org/x/ cases/furundzija/tjug/en/fur-tj981210e.pdf 
Caso Blake vs. Guatemala (1999): Sentencia, Reparaciones y Costas, Corte Interamericana de Derechos Humanos, 22 de enero de 1999, Serie C No 48, (fecha de consulta: 15 de junio de 2010). Disponible en http://www.corteidh.or.cr/docs/casos/articulos/seriec_48_esp.pdf

Case Prosecutor v. Jelisic(1999):Sentencia, Tribunal Penal Internacional para la ex Yugoslavia, Caso No IT-95-10, 14 de diciembre 1999, (fecha de consulta:26 de noviembre de 2010). Disponible en <http://www.icty.org/x/cases/jelisic/ tjug/en/jel-tj991214e.pdf

Case Prosecutor v. Kayishema and Ruzindana(1999): Sentencia, Tribunal Penal Internacional para Ruanda, Casos nos ICTR-95-1-T, 21 de mayo de 1999, (fecha de consulta: 17 de junio de 2010). Disponible en http://www.unictr. org/Portals/0/Case/English/Kayishema_F/decisions/index.pdf

Cyprus v. Turkey(1999): Reporte, Comisión Europea de Derechos Humanos, 4 de junio de 1999, (fecha de consulta: 17 de junio de 2010). Disponible en http://cmiskp.echr.coe.int/tkp197/search.asp?sessionid=55591069\&sk in=hudoc-en

Case Prosecutor v. Kupreskic et al (2000): Sentencia,Tribunal Penal Internacional para la ex Yugoslavia, Caso noIT-95-16-T, 14 de enero de 2000, (fecha de consulta: 17 de junio de 2010). Disponible en http://www.icty.org/x/cases/ kupreskic/tjug/en/kup-tj000114e.pdf

Requerimiento respecto del Convenio No 169, Sobre Pueblos Indígenas y Tribales en Paises Independientes, adoptado por la Organización Internacional del Trabajo, el 27 de junio de 1989 (2000): Tribunal Constitucional, 4 de agosto de 2000, Rol No 309, (fecha de consulta: 2 de junio de 2011). Disponible en el Sitio Web del Tribunal Constitucional, http://www.tribunalconstitucional.cl

Al-Adsani v. TheUnitedKingdom(2001): Sentencia,Corte Europea de Derechos Humanos, 21 de noviembre de 2001, (fecha de consulta: 17 de junio de 2010). Disponible en http://cmiskp.echr.coe.int/tkp197/search.asp?sessio nid $=55591069 \&$ skin $=$ hudoc-en

Case Prosecutor v. Krstic(2001): Sentencia, Tribunal Penal Internacional para la ex Yugoslavia, Caso No IT-98-33, 2 de agosto de 2001, (fecha de consulta: 26 de noviembre de 2010). Disponible en http://www.icty.org/x/cases/ $\mathrm{krstic} / \mathrm{tjug} / \mathrm{en} / \mathrm{krs}-\mathrm{tj} 010802 \mathrm{e} . \mathrm{pdf}$

Case Prosecutor v. Kunarac et al (2001): Sentencia,Tribunal Penal Internacional para la ex Yugoslavia, Casos nos IT-96-23-T and IT-96-23/1, 22 de febrero de 2001, (fecha de consulta: 17 de junio de 2010). Disponible en http:// www.icty.org/x/cases/kunarac/tjug/en/kun-tj010222e.pdf 
Caso Barrios Altos vs. Perú (2001): Sentencia, Fondo, Corte Interamericana de Derechos Humanos, 14 de marzo de 2001, Serie C No 75, (fecha de consulta: 15 de junio de 2010). Disponible en http://www.corteidh.or.cr/docs/casos/ articulos/seriec_75_esp.pdf

Demanda de inconstitucionalidad contra el artículo 322a (parcial) del Código Penal, creado por el artículo primero de la Ley 589 de 2000 "Por medio de la cual se tipifica el genocidio, la desaparición forzada, el desplazamiento forzado y la tortura; y se dictan otras disposiciones" (2001): Corte Constitucional colombiana, 14 de febrero de 2001, recurso No D-3120, Ponente Fabio Morón Díaz, sentencia No C-177/01, Base de Datos VLEX No 43614422.

Case Prosecutor v. Simic(2002): Sentencia,Tribunal Penal Internacional para la ex Yugoslavia, Caso No IT-95-9/2-S, 17 de octubre de 2002, (fecha de consulta: 26 de noviembre de 2010).Disponible en http://www.icty.org/x/ cases/milan_simic/tjug/en/sim-sj021017e.pdf

Demanda de inconstitucionalidad contra el artículo 13 de la Ley 733 de 2002 (2002): Corte Constitucional colombiana, 28 de agosto de 2002, recurso No D-3945, sentencia No C-695/02, Base de Datos VLEX No 43618896.

Case Prosecutor v. Naletilic and other(2003): Sentencia, Tribunal Penal Internacional para la ex Yugoslavia, Caso No IT-98-34, 30 de marzo de 2003, (fecha de consulta: 26 de noviembre de 2010). Disponible en http://www. icty.org/x/cases/naletilic_martinovic/tjug/en/nal-tj030331-e.pdf

Case Prosecutor v. Stakic (2003):Sentencia, Tribunal Penal Internacional para la ex Yugoslavia, Caso No IT-97-24-T, 31 de julio de 2003, (fecha de consulta: 17 de junio de 2010). Disponible en http://www.icty.org/x/cases/stakic/ tjug/en/stak-tj030731e.pdf

Condición Jurídica y Derechos de los Migrantes Indocumentados (2003): Opinión Consultiva OC-18/03, Corte Interamericana de Derechos Humanos, 17 de septiembre de 2003, Serie A No 18, (fecha de consulta: 15 de junio de 2010). Disponible en http://www.corteidh.or.cr/docs/opiniones/seriea_18_esp.pdf

Ríos (2003): Tribunal Supremo de Justicia de Venezuela, Sala Constitucional, 5 de junio de 2003, recurso de nulidad por inconstitucionalidad, expediente No 00-1401, Ponente Antonio García García, Base de Datos VLEX No 29415643.

Case Prosecutor v. Brdjanin(2004): Sentencia,Tribunal Penal Internacional para la ex Yugoslavia, Caso No IT-99-36, 1 de septiembre de 2004, (fecha de 
consulta: 26 de noviembre de 2010). Disponible en http://www.icty.org/x/ cases/brdanin/tjug/en/brd-tj040901e.pdf

Caso de las Hermanas Serrano Cruz vs. El Salvador (2004): Sentencia, Excepciones Preliminares, Corte Interamericana de Derechos Humanos, 23 de noviembre de 2004, Serie C No 118, (fecha de consulta: 15 de junio de 2010). Disponible en http://www.corteidh.or.cr/docs/casos/articulos/seriec_118_esp.pdf

Caso Masacre Plan de Sánchez vs. Guatemala (2004): Sentencia, Fondo, Corte Interamericana de Derechos Humanos, 29 de abril de 2004, Serie C No 105, (fecha de consulta: 15 de junio de 2010). Disponible en http://www.corteidh.or.cr/docs/casos/articulos/seriec_105_esp.pdf

Legal Consequences of the Construction of a Wall in the Occupied Palestinian Territory (2004): Opinión Consultiva, Corte Internacional de Justicia, 9 de julio de 2004, (fecha de consulta: 15 de junio de 2010). Disponible en http://www.icj-cij.org/docket/files/131/1671.pdf

Xenides-Arestis v. Turkey (2004): Decisión de admisibilidad, Corte Europea de Derechos Humanos, 2 de septiembre de 2004, (fecha de consulta: 17 de junio de 2010). Disponible en http://cmiskp.echr.coe.int/tkp197/search.a sp? sessionid $=55591069$ \&skin $=$ hudoc - en

Case Prosecutor v. Blagojevic (2005): Sentencia, Tribunal Penal Internacional para la ex Yugoslavia, Caso No IT-02-60, 17 de enero de 2005, (fecha de consulta: 26 de noviembre de 2010). Disponible en http://www.icty.org/x/ cases/blagojevic_jokic/tjug/en/bla-050117e.pdf

Contra Gómez Aguilar (2006): Corte de Apelaciones de Santiago, 18 de enero de 2006, Rol No 37483-2004, Westlaw CL/JUR/7724/2006.

Estado de Chile y otros con Rivera (2006): Corte de Apelaciones de Santiago, 8 de noviembre de 2006, Rol No 5937-2006, Westlaw CL/JUR/6802/2006.

Fiscalía Judicial y otros con Ruiz, Madrid, Corbalán y Díaz (2006): Corte de Apelaciones de Santiago, 27 de junio de 2006, Rol No 14058-04, Westlaw CL/JUR/8497/2006.

Case of Jorgic v. Germany (2007): Sentencia, Corte Interamericana de Derechos Humanos, 12 de julio de 2007, (fecha de consulta: 17 de junio de 2010). Disponible en http://cmiskp.echr.coe.int/tkp197/search.asp?sessionid=55 591069\&skin=hudoc-en

Lejderman con Polanco y otros (2007): Corte de Apelaciones de Santiago, 18 de diciembre de 2007, Rol No 11801-2006, Westlaw CL/JUR/6802/2007. 
Toro y otros con Contreras y otros (2007): Corte de Apelaciones de Santiago, 18 de diciembre de 2007, Rol No 1579-2007, Westlaw CL/JUR/5490/2007.

Urrutia con Ruiz y otros (2007): Corte de Apelaciones de Santiago, 2 de agosto de 2007, Rol No 14281-2006, Westlaw CL/JUR/6261/2007.

Case of Demir and Baykara v. Turkey (2008): Sentencia, Corte Europea de Derechos Humanos, 12 de noviembre de 2008, (fecha de consulta: 17 de junio de 2010). Disponible en http://cmiskp.echr.coe.int/tkp197/search.a sp?sessionid $=55591069$ \&skin=hudoc-en

Caso Del Penal Miguel Castro Castro vs. Perú (2008): Interpretación de la Sentencia de Fondo, Reparaciones y Costas, Corte Interamericana de Derechos Humanos, 2 de agosto de 2008, Serie C No 181, (fecha de consulta: 15 de junio de 2010). Disponible en http://www.corteidh.or.cr/docs/casos/ articulos/seriec_181_esp.pdf

Lagos y otros con Guerra y otro (2008): Corte Suprema, 25 de septiembre de 2008, Rol No 4662-2007, (fecha de consulta: 28 de febrero de 2012). Disponible en el sitio web del Poder Judicial, http://www.poderjudicial.cl/modulos/ BusqCausas/BCA_esta402.php? rowdetalle=AAANoPAALAABifdAAG\&c onsulta $=100 \&$ causa $=4662 / 2007 \&$ numcua $=26714 \&$ secre $=$ UNICA

Revisión constitucional de la Ley No 1.072 del 31 de julio de 2006, "Por medio de la cual se aprueba 'La Enmienda al articulo $1^{\circ}$ de la Convención sobre Prohibiciones o Restricciones del Empleo de Ciertas Armas Convencionales que puedan considerarse excesivamente nocivas o de efectos indiscriminados' adoptada en la segunda conferencia de examen de los Estados Parte en la convención, el veintiuno (21) de diciembre de dos mil uno (2001), en Ginebra, Suiza” (2008): Corte Constitucional colombiana, 28 de mayo de 2008, Ponente Rodrigo Escobar Gil, sentencia No C-534/08, Base de datos VLEX No 43476808.

Case of Opuz v. Turkey (2009): Sentencia, Corte Europea de Derechos Humanos, 9 de junio de 2009, (fecha de consulta: 17 de junio de 2010). Disponible en http://cmiskp.echr.coe.int/tkp197/search.asp?sessionid=55591069\&sk in=hudoc-en

Caso De la Masacre de las Dos Erres vs. Guatemala (2009): Excepción Preliminar, Fondo, Reparaciones y Costas, Corte Interamericana de Derechos Humanos, 24 de noviembre de 2009, Serie C No 211, (fecha de consulta: 17 de junio de 2010). Disponible en < http://www.corteidh.or.cr/docs/casos/articulos/ seriec_211_esp.pdf

Lejderman con Polanco y otros (2009): Corte Suprema, 25 de mayo de 2009, Rol No 696-2008, (fecha de consulta: 28 de febrero de 2012). Disponible en 
el sitio web del Poder Judicial, http://www.poderjudicial.cl/modulos/BusqCausas/BCA_esta402.php?rowdetalle=AAANoPAALAAB4ClAAE\&consu $\mathrm{lta}=100 \&$ causa $=696 / 2008 \&$ numcua $=15814 \&$ secre $=$ UNICA

Rojas con Fisco de Chile (2010): Corte Suprema, 14 de diciembre de 2010, Rol No 6458-2008, voto disidente del abogado integrante MuÑOz, (fecha de consulta: 28 de febrero de 2012). Disponible en el sitio web del Poder Judicialhttp://www.poderjudicial.cl/modulos/BusqCausas/BCA_esta402. php? rowdetalle $=$ AAANoPAAyAAB 1 nrAAF $\&$ consulta $=100 \&$ causa $=6458 /$ 2008\&numcua $=48013 \&$ secre $=$ UNICA

Case of Othman (Abu Qatada) v. The United Kingdom (2012): Sentencia, Corte Europea de Derechos Humanos, 17 de enero de 2012, (fecha de consulta: 2 de marzo de 2012). Disponible en http://cmiskp.echr.coe.int/tkp197/ view.asp?item $=6 \&$ portal $=\mathrm{hbkm} \&$ action $=\mathrm{h} t \mathrm{ml} \&$ highlight $=$ cogens \&sessio nid $=87532219 \&$ skin $=$ hudoc-en

\section{Normas Jurídicas CitadAs}

Carta Africana de Derechos Humanos y de los Pueblos. Aprobada el 27 de julio de 1981, durante la XVIII Asamblea de Jefes de Estado y Gobierno de la Organización de la Unidad Africana, reunida en Nairobi, Kenya. En vigor desde el 21 de octubre de 1986.

Carta Árabe de Derechos Humanos. Liga de Estados Árabes, 22 de mayo de 2004, entró en vigor el 15 de marzo de 2008.

Carta de Derechos Fundamentales de la Unión Europea (2010/C 83/02). Diario Oficial de la Unión Europea, 30 de marzo de 2010.

Carta de las Naciones Unidas (1945). La Ley No 8.402, publicada el 3 de enero de 1946, dispone cumplir y llevar a efecto como Ley de la República de Chile la Carta de las Naciones Unidas.

Constitución Política de la República de Chile de 1980 actualizada con Reforma del año 2005, Decreto 100 Fija el texto refundido, coordinado y sistematizado. Diario Oficial, 22 septiembre 2005.

Convención Americana sobre Derechos Humanos (22 de noviembre de 1969, San José de Costa Rica). Promulgada en Chile por Decreto Supremo No 873, publicado en el Diario Oficial el 5 de enero de 1991.

Convención contra la tortura y otros tratos o penas crueles, inhumanos o degradantes (ONU, 10 de diciembre de 1984). Promulgada en Chile por el Decreto 
Supremo del Ministerio de Relaciones Exteriores No 808, Diario Oficial, 26 de noviembre de 1988.

Convención de Viena sobre el Derecho de los Tratados (23 de mayo de 1969). Promulgada en Chile por el Decreto Supremo del Ministerio de Relaciones Exteriores No 381, Diario Oficial, 22 de junio de 1981.

Convención interamericana para prevenir y sancionar la tortura (OEA, 9 diciembre 1985). Promulgada en Chile por el Decreto Supremo del Ministerio de Relaciones Exteriores No 809, Diario Oficial, 26 de noviembre de 1988.

Convención interamericana sobre desaparición forzada de personas (OEA, 1994). Promulgada por Decreto No 12 del Ministerio de Relaciones Exteriores. Diario Oficial, 24 de febrero de 2010.

Convención internacional contra el apartheid en los deportes. Adoptada y abierta a la firma y ratificación por la Asamblea General de la ONU en su resolución 40/64 G, 10 de diciembre de 1985. Entra en vigor el 3 de abril de 1988, de conformidad con el artículo 18 (1). http://treaties.un.org/Pages/ ViewDetails.aspx?src=IND\&mtdsg_no=IV-10\&chapter=4\&lang=en - \# (Proyecto de acuerdo en Chile ingresado a tramitación en 1990, archivado sin haberse aprobado en 1994, No Boletín: 213-10).

Convención internacional para la protección de todas las personas contra las desapariciones forzadas (Nueva York, 20 diciembre 2006). Entra en vigor internacional el 23 de diciembre de 2010 con la $20^{\circ}$ ratificación. Promulgada en Chile mediante Decreto Supremo No 280 del Ministerio de Relaciones Exteriores, de 10 de diciembre de 2010, publicado en el Diario Oficial el 16 abril 2011.

Convención internacional sobre la represión y el castigo del crimen de apartheid, Adoptada y abierta a la firma y ratificación por la Asamblea General en su resolución 3068 (XXVIII), de 30 de noviembre de 1973. Entra en vigor el 18 de julio de 1976, de conformidad con el artículo XV. (Proyecto de acuerdo en Chile ingresado a tramitación en 1990, archivado sin ser aprobado en 1994, No Boletín: 214-10).

Convención para la prevención y la sanción del delito de genocidio, aprobada en la $3^{a}$ Asamblea General de las Naciones Unidas, en París el 11 de diciembre 1948. Promulgada en Chile por el Decreto Supremo del Ministerio de Relaciones Exteriores No 316, Diario Oficial, 11 de diciembre de 1953.

(I.) Convenio de Ginebra del 12 de agosto de 1949 para Aliviar la Suerte que Corren los Heridos y los Enfermos de las Fuerzas Armadas en campaña. Promulgado en Chile por Decreto Supremo No 752, Diario Oficial, 17 de abril de 1951. 
(II). Convenio de Ginebra del 12 de agosto de 1949 para Aliviar la Suerte que Corren los Heridos, los Enfermos y los Náufragos de las Fuerzas Armadas en el Mar. Promulgado en Chile por Decreto Supremo No 752, Diario Oficial, 18 de abril de 1951.

(III). Convenio de Ginebra del 12 de agosto de 1949 relativo al trato debido a los prisioneros de guerra. Promulgado en Chile por Decreto Supremo No 752, Diario Oficial, 19 de abril de 1951.

(IV.) Convenio de Ginebra del 12 de agosto de 1949 relativo a la protección debida a las personas civiles en tiempo de guerra. Promulgado en Chile por Decreto Supremo No 752, Diario Oficial, 20 de abril de 1951.

Convenio Europeo para la Prevención de la Tortura y de las Penas o Tratos Inhumanos o Degradantes. Comité de Ministros del Consejo de Europa, 26 de junio de 1987. Serie de Tratados Europeos No 126. Modificado a tenor de lo dispuesto en los Protocolos No 1 (ETS No 151) y No 2 (ETS No 152) que entraron en vigor el 1 de marzo de 2002.

Convenio para la Protección de los Derechos Humanos y de las Libertades Fundamentales (Conocido como Convenio Europeo de Derechos Humanos). Consejo de Europa, Roma, 4 de noviembre de 1950. Secretaría del Tribunal Europeo de Derechos Humanos, junio de 2010, versión del texto revisado de conformidad con los Protocolos $\mathrm{No}_{s} .11$ y 14, y completado por el Protocolo adicional y los Protocolos Nos. 4, 6, 7, 12 y 13.

Declaración Americana de los Derechos y Deberes del Hombre.Aprobada en la Novena Conferencia Internacional Americana Bogotá, Colombia, 1948.

Declaración de El Cairo sobre Derechos Humanos en el Islam. Conferencia Mundial de los estados miembros de la Organización de la Conferencia Islámica, 5 de agosto de 1990. Documento ONU A/CONF.157/PC/62/ Add.18 (1993).

Declaración sobre la protección de todas las personas contra la tortura y otros tratos o penas crueles, inhumanos o degradantes. Adoptada por la Asamblea General de la ONU en su resolución 3452 (XXX), de 9 de diciembre de 1975.

Declaración sobre la protección de todas las personas contra las desapariciones forzadas. Aprobada por la Asamblea General de la ONU en su resolución 47/133 de 18 de diciembre 1992.

Declaración Universal de Derechos Humanos. Asamblea General de las Naciones Unidas, 10 de diciembre de 1948.

Estatuto de Roma de la Corte Penal Internacional, aprobado en Roma el 17 julio 1998. 
Estatuto del Tribunal Militar Internacional de Nüremberg, adoptado el 6 de octubre de 1945.

Estatuto del Tribunal Penal Internacional para la ex Yugoslavia, 25 de mayo de 1993.

Estatuto del Tribunal Penal Internacional para Ruanda, 8 noviembre 1994.

Ley (belga) relativa a las violaciones graves de derecho internacional humanitario promulgada el 5 de agosto de 2003.

Pacto Internacional de Derechos civiles y politicos, adoptado por la Asamblea General de las Naciones Unidas por resolución No 2.200, el 16 de diciembre de 1966. Promulgado en Chile medianteDecreto No 778, publicado en el Diario Oficial el 29 de abril de 1989.

Protocolos Adicionales I y II a los Convenios de Ginebra de 1949, relativos a la Protección de las Víctimas de los Conflictos Armados Internacionales y a la Protección de las Víctimas de los Conflictos Armados sin Carácter Internacional, adoptados 1977. Promulgados en Chile por Decreto No 752, publicado en el Diario Oficial el 28 de octubre de 1991. 
